\title{
Cochrane
}

Library

Cochrane Database of Systematic Reviews

\section{Antibiotic therapy for prophylaxis against infection of pancreatic necrosis in acute pancreatitis (Review)}

Villatoro E, Mulla M, Larvin M

Villatoro E, Mulla M, Larvin M.

Antibiotic therapy for prophylaxis against infection of pancreatic necrosis in acute pancreatitis.

Cochrane Database of Systematic Reviews 2010, Issue 5. Art. No.: CD002941.

DOI: 10.1002/14651858.CD002941.pub3.

www.cochranelibrary.com

Antibiotic therapy for prophylaxis against infection of pancreatic necrosis in acute pancreatitis (Review) Copyright $\odot 2010$ The Cochrane Collaboration. Published by John Wiley \& Sons, Ltd. 
TABLE OF CONTENTS

HEADER 1

ABSTRACT

PLAIN LANGUAGE SUMMARY

BACKGROUND

OBJECTIVES

METHODS

RESULTS

Figure 1.

DISCUSSION

AUTHORS' CONCLUSIONS

ACKNOWLEDGEMENTS

REFERENCES

CHARACTERISTICS OF STUDIES

DATA AND ANALYSES

Analysis 1.1. Comparison 1 Antibiotics versus control, Outcome 1 Mortality.

Analysis 1.2. Comparison 1 Antibiotics versus control, Outcome 2 Infected Pancreatic Necrosis.

Analysis 1.3. Comparison 1 Antibiotics versus control, Outcome 3 Non-Pancreatic Infections.

Analysis 1.4. Comparison 1 Antibiotics versus control, Outcome 4 All sites infections.

Analysis 1.5. Comparison 1 Antibiotics versus control, Outcome 5 Fungal Infection.

Analysis 1.6. Comparison 1 Antibiotics versus control, Outcome 6 Operative Treatment.

Analysis 2.1. Comparison 2 Beta-lactam versus control, Outcome 1 Mortality (beta-lactam).

Analysis 2.2. Comparison 2 Beta-lactam versus control, Outcome 2 Infected Pancreatic Necrosis (beta-lactam).

Analysis 2.3. Comparison 2 Beta-lactam versus control, Outcome 3 Non-Pancreatic Infections (beta-lactam).

Analysis 2.4. Comparison 2 Beta-lactam versus control, Outcome 4 All sites infections (beta-lactam).

Analysis 2.5. Comparison 2 Beta-lactam versus control, Outcome 5 Fungal Infection (beta-lactam).

Analysis 2.6. Comparison 2 Beta-lactam versus control, Outcome 6 Operative Treatment (beta-lactam).

Analysis 3.1. Comparison 3 Quinolone versus control, Outcome 1 Mortality (quinolones).

Analysis 3.2. Comparison 3 Quinolone versus control, Outcome 2 Infected Pancreatic Necrosis (quinolones).

Analysis 3.3. Comparison 3 Quinolone versus control, Outcome 3 Fungal Infection (quinolones).

Analysis 4.1. Comparison 4 Imipenem versus control, Outcome 1 Mortality (imipenem).

Analysis 4.2. Comparison 4 Imipenem versus control, Outcome 2 Infected Pancreatic Necrosis (imipenem).

Analysis 4.3. Comparison 4 Imipenem versus control, Outcome 3 Non-pancreatic infections (imipenem).

Analysis 4.4. Comparison 4 Imipenem versus control, Outcome 4 All sites infections (imipenem).

Analysis 4.5. Comparison 4 Imipenem versus control, Outcome 5 Fungal Infection (imipenem).

Analysis 4.6. Comparison 4 Imipenem versus control, Outcome 6 Operative Treatment (imipenem). APPENDICES

WHAT'S NEW

HISTORY

CONTRIBUTIONS OF AUTHORS

DECLARATIONS OF INTEREST

SOURCES OF SUPPORT

DIFFERENCES BETWEEN PROTOCOL AND REVIEW

NOTES

INDEX TERMS 
[Intervention Review]

\section{Antibiotic therapy for prophylaxis against infection of pancreatic necrosis in acute pancreatitis}

Eduardo Villatoro ${ }^{1}$, Mubashir Mulla1, Mike Larvin ${ }^{1}$

1Academic Division of Surgery, School of Graduate Entry Medicine, University of Nottingham, Derby, UK

Contact address: Mike Larvin, Academic Division of Surgery, School of Graduate Entry Medicine, University of Nottingham, Derby City General Hospital, Uttoxeter Road, Derby, Derbyshire, DE22 3DT, UK. mlarvin@rcseng.ac.uk.

Editorial group: Cochrane Upper GI and Pancreatic Diseases Group.

Publication status and date: New search for studies and content updated (conclusions changed), published in Issue 5, 2010.

Citation: Villatoro E, Mulla M, Larvin M. Antibiotic therapy for prophylaxis against infection of pancreatic necrosis in acute pancreatitis. Cochrane Database of Systematic Reviews 2010, Issue 5. Art. No.: CD002941. DOI: 10.1002/14651858.CD002941.pub3.

Copyright @ 2010 The Cochrane Collaboration. Published by John Wiley \& Sons, Ltd.

\section{A B S T R A C T}

\section{Background}

Pancreatic necrosis may complicate severe acute pancreatitis, and is detectable by computed tomography (CT). If it becomes infected mortality increases, but the use of prophylactic antibiotics raises concerns about antibiotic resistance and fungal infection.

\section{Objectives}

To determine the efficacy and safety of prophylactic antibiotics in acute pancreatitis complicated by CT proven pancreatic necrosis.

\section{Search methods}

Searches were updated in November 2008, in The Cochrane Library (Issue 2, 2008), MEDLINE, EMBASE, and CINAHL. Conference proceedings and references from found articles were also searched.

\section{Selection criteria}

Randomised controlled trials (RCTs) comparing antibiotics versus placebo in acute pancreatitis with CT proven necrosis.

\section{Data collection and analysis}

Primary outcomes were mortality and pancreatic infection rates. Secondary end-points included non pancreatic infection, all sites infection, operative rates, fungal infections, and antibiotic resistance. Subgroup analyses were performed for antibiotic regimen (betalactam, quinolone, and imipenem).

\section{Main results}

Seven evaluable studies randomised 404 patients. There was no statistically significant effect on reduction of mortality with therapy: $8.4 \%$ versus controls $14.4 \%$, and infected pancreatic necrosis rates: $19.7 \%$ versus controls $24.4 \%$. Non-pancreatic infection rates and the incidence of overall infections were not significantly reduced with antibiotics: $23.7 \%$ versus $36 \% ; 37.5 \%$ versus $51.9 \%$ respectively. Operative treatment and fungal infections were not significantly different. Insufficient data were provided concerning antibiotic resistance.

With beta-lactam antibiotic prophylaxis there was less mortality (9.4\% treatment, $15 \%$ controls), and less infected pancreatic necrosis (16.8\% treatment group, $24.2 \%$ controls) but this was not statistically significant. The incidence of non-pancreatic infections was nonsignificantly different ( $21 \%$ versus $32.5 \%$ ), as was the incidence of overall infections ( $34.4 \%$ versus $52.8 \%)$, and operative treatment rates. No significant differences were seen with quinolone plus imidazole in any of the end points measured. Imipenem on its own showed no difference in the incidence of mortality, but there was a significant reduction in the rate of pancreatic infection $(p=0.02 ; \mathrm{RR} 0.34,95 \% \mathrm{Cl}$ 0.13 to 0.84$)$. 


\section{Authors' conclusions}

No benefit of antibiotics in preventing infection of pancreatic necrosis or mortality was found, except for when imipenem (a beta-lactam) was considered on its own, where a significantly decrease in pancreatic infection was found. None of the studies included in this review were adequately powered. Further better designed studies are needed if the use of antibiotic prophylaxis is to be recommended.

\section{PLAIN LANGUAGE SUMMARY}

\section{Use of antibiotics to prevent infection of dead pancreatic tissue in acute pancreatitis}

Acute pancreatitis is the inflammation of the pancreas, a serious emergency with no specific treatment. The pancreas, a digestive gland, can become inflamed for many reasons, but mainly as a complication from gallstones or excess alcohol intake. If severe, the pancreas may lose its blood supply, a complication called pancreatic necrosis that can be detected by computed tomography (CT) scanning. Death can occur either early in the disease process in association with uncontrolled inflammatory responses, causing multiple organ-system failure (MOSF), or late when the necrotic tissue becomes infected, which might necessitate major surgery to remove the infection, with the risk of death rising from $10 \%$ to over $40 \%$. Antibiotics may prevent later infection and reduce the risk of death, but could also encourage bacterial antibiotic resistance and fungal infections. Controlled trials looking at the value of using prophylactic antibiotics have produced conflicting results.

This review aims to determine the effectiveness and safety of prophylactic antibiotics in CT-proven necrotising acute pancreatitis. A previous version published in 2006 suggested a survival advantage overall, and a decrease in pancreatic infections for some types of antibiotic therapy (beta-lactam antibiotics). Since that review, two further studies have been published: both were double-blinded, randomised, clinical trials (RCTs). These studies have now been included and our conclusions have changed as a result.

In the current review, data were found and analysed from 7 trials involving 404 patients randomly allocated to receive antibiotics or placebo. Although death occurred less after antibiotics (8.4\%) than placebo (14.4\%), as did infected pancreatic necrosis (19.7\% versus $24.4 \%)$ and other infections (23.7\% versus $36 \%)$, the differences were not statistically significant and so genuine benefit cannot be confirmed. There were no major problems with antibiotic resistance, and fungal infections were similar (3.9\% versus $5 \%$ ). The quality of studies was variable and only two were 'blinded', whereby investigators and patients were unaware of which treatment patients received. Many different regimens were used, and of the two main types of antibiotics used, a beta-lactam appeared to work better. Only one type of antibiotic (imipenem) was considered on its own, showing a significant decrease in infection of the pancreatic necrosis.

Although we cannot confirm benefit from the use of prophylactic antibiotics in this condition, consistent trends towards a beneficial effect nevertheless remain. Further, better designed studies, ideally with beta-lactam antibiotics, are required. 


\section{B A C K G R O U N D}

\section{Description of the condition}

Acute pancreatitis is a common acute abdominal emergency, with an apparently rising incidence (Tinto 2002; Goldacre 2004, Sandzén 2009). No specific treatment is available, and the inhospital case mortality rate of 5 to $10 \%$ (Bradley 1993) has remained fairly static for over four decades. Death usually occurs in association with uncontrolled local and systemic inflammatory responses, causing pancreatic necrosis and multiple organ-system failure (MOSF). Management consists of intensive therapy should MOSF develop, with invasive interventions for complications of pancreatic necrosis. The mortality risk can increase to as much as $40 \%$ if initially sterile pancreatic necrosis becomes infected, following which surgical, endoscopic, or percutaneous debridement is often required (Beger 1986; Bradley 1989; Larvin 1989; Larvin 2008; Bradley 1993; Bassi 1994a; Bassi 1994b; Isenmann 1994; Ho 1997; Dervenis 1999; Farkas 1996; Büchler 2000; Werner 2003; Werner 2005). The infecting agents are usually gutderived bacteria (Garg 2001), and they are thought to migrate via the pancreatic duct from the duodenum, or from adjacent bowel either via intervening lymphatics or directly, as gut mucosal defences against bacterial translocation become impaired in severe acute pancreatitis (Ammori 1999; Rahman 2003).

It has long been known that pancreatic necrosis can be established as early as the time of admission to hospital, when contrastenhanced computed tomography (CT) is undertaken (Larvin 1990), but superinfection may later manifest with a second period of multiple organ-system failure. Thus there exists a window of opportunity of around 1-2 weeks during which superinfection may be prevented by administering antibacterial therapy (Beger 1986; Barie 1996; Bassi 1994a; Steinberg 1994). Although antibiotics known to penetrate viable pancreatic tissue may not penetrate areas of necrosis effectively, high microbicidal levels can be achieved in adjacent tissues (Burns 1986; Büchler 1992; Bassi 1994b; Bertazzoni 1996; Foitzik 1997; Bassi 1998; Kramer 1999). High circulating levels should also prevent infection via haematogenous and lymphatic routes (Barie 1996). Attempts have been made to incorporate gastro-intestinal tract decontamination, which includes antibacterial agent administration (Luiten 1995; Luiten 1999). It is feared that the administration of potent antibacterial therapy for 2 weeks or more could potentially increase the risks of antibacterial resistance and facilitate opportunistic fungal infection (Eatock 1999).

\section{Description of the intervention}

Following a relatively small number of controlled and uncontrolled trials, enthusiasm for prophylaxis was expressed through a number of influential journal articles and editorials (Bradley 1989; Johnson 1996; Foxx-Orenstein 1997; Golub 1998; Powell 1998; Bradley 1999; Ratschko 1999; Rünzi 1999). A United Kingdom (UK) survey suggested that almost $90 \%$ of surgeons applied prophylaxis (Powell 1999). Although trials were underpowered and generated variable results, meta-analyses suggested that mortality or morbidity could be reduced (Powell 1999; Golub 1998; Sharma 2001). However, there has been increasing concern over adverse effects. Some $11 \%$ of specialists responding to the above mentioned UK survey reported adverse effects attributable to antibiotic administration (Powell 1999), including antimicrobial resistance and opportunistic fungal infection affecting excised necrotic sequestra, blood and remote sites.

There has been a steady rise in the emergence of resistant organisms in general, but there are few reliable sources of data on whether increased antibacterial prophylaxis is associated with rising antimicrobial resistance or Candida infection in infected pancreatic necrosis. Other factors involved might include more changes in bacterial ecology due to increased general usage of antibacterial therapy, and increasing use of central venous catheters for monitoring and parenteral nutrition. In one series of 46 patients with infected pancreatic necrosis, resistant bacteria were yielded from 52\%, with increasing risk in proportion to the duration of prophylaxis (De Waele 2004). In a large series of infected pancreatic necrosis cases published prior to wide usage of prophylaxis, the predominant infecting organisms were Escherichia coli and Bacteroides species with an incidence of Candida infection of only 2.6\% (Beger 1986). A study of two different prophylactic antibacterial regimens found the most isolated microorganisms in pancreatic necrosis specimens were methicillin resistant Staphylococcus aureus (MRSA) (8.3\%) and Candida glabrata (6.6\%) (Bassi 1998). Another study comparing 14 days of imipenem-cilastatin versus more prolonged therapy reported an incidence of Candida infection in pancreatic necrosis of $2 \%$, with remote Candida infection rates of $6.5 \%$ after 14 days rising to $13 \%$ with more prolonged treatment (Maravi-Poma 2003). A furtFher study compared pancreatic necrosis patients treated before and after the introduction of routine prophylaxis, and indicated a shift from mainly gram-negative to mostly grampositive infection, without significant resistance or fungal infection (Howard 2002). This has led some investigators to advocate the inclusions of antifungal prophylaxis for patients with pancreatic necrosis receiving prophylactic antibiotics (Grewe 1999; De Waele 2003).

A counter argument is that the mere presence of Candida within pancreatic necrosis may indicate only colonisation. One study argued that outcome was unaffected if Candida species had been identified and promptly treated (Gloor 2001), whilst two other studies suggest the contrary (Gotzinger 2001; Connor 2004).

Clearly it is impossible to continuously sample necrotic areas, and thus Candida infection may go unrecognised and untreated. The question of whether Candida colonisation constitutes a sufficiently serious risk to make a case against antibacterial prophylaxis was discussed in a journal editorial (O'Reilly 2004), but there are scant data on which to draw a firm conclusion.

\section{Why it is important to do this review}

A previous version of this review published in 2006 (Villatoro 2006) suggested a survival advantage overall, and a decrease in pancreatic sepsis for the beta-lactam therapy group. Since that review two further studies have been published: both were doubleblinded, randomised, clinical trials (RCTs) (Dellinger 2007; Røkke 2007). These studies have now been included. The conclusions of this review have changed as a result of the inclusion of these two studies. 


\section{O B JECTIVES}

To determine the efficacy and safety of prophylactic antibiotic therapy in patients suffering from severe acute pancreatitis proven to have developed pancreatic necrosis.

\section{METHODS}

\section{Criteria for considering studies for this review}

\section{Types of studies}

Randomised controlled trials (RCTs) in which prophylactic antibiotic therapy was evaluated in severe acute pancreatitis with proven pancreatic necrosis, in comparison with placebo therapy and best supportive care.

\section{Types of participants}

Patients with severe acute pancreatitis in whom pancreatic necrosis has been diagnosed by intravenous contrast enhanced CT according to internationally agreed criteria (Atlanta and Santorini criteria) (Bradley 1993; Dervenis 1999).

\section{Types of interventions}

Antibacterial therapy administered with the intention of preventing the infection of pancreatic necrosis, commenced within seven days of onset of the attack. Trials which combined antibacterial therapy with selective decontamination or other type of intervention were not be considered.

\section{Types of outcome measures}

\section{Primary outcomes}

All cause mortality and rates of microbiologically proven infected pancreatic necrosis (needle aspirate or operative samples)

\section{Secondary outcomes}

Rates of microbiologically proven non-pancreatic infection (respiratory, urinary, central venous line sepsis) from appropriate samples, overall infection rates (pancreatic and non-pancreatic), operative rates for debridement of pancreatic necrosis, opportunistic fungal infections, and reported incidence of antimicrobial drug resistant infections.

\section{Search methods for identification of studies}

Searches were conducted to identify all published and unpublished randomised controlled trials (RCTs). The search strategy identified studies in all languages and, when necessary, non English language papers were translated so that they could be fully assessed for potential inclusion in the review.

Trials were identified by searching the Cochrane Library (Issue 2 - 2008), MEDLINE (January 1966 - November 2008), EMBASE (January 1980 - November 2008) and CINAHL (January 1982 - November 2008). This was updated from previous published reviews. All search strategies (Appendix 1; Appendix 2; Appendix 3) were constructed by using a combination of subject headings and text words relating to the use of antibiotics for the treatment of acute pancreatitis. The standard Cochrane search strategy filter for identifying randomised controlled trials was applied to all searches.
Reference lists from the trials selected by electronic searching were hand searched to identify further relevant trials.

The following conference abstracts were hand searched to identify further potentially relevant studies for inclusion in the review:

- American Hepato-Pancreato-Biliary Association (AHPBA)

- American Pancreatic Association

- Association of Upper GI Surgeons (AUGIS)

- British Society of Gastroenterology

- Digestive Diseases Week

- European Pancreatic Club

- International Association of Pancreatology

- International Hepatobiliary Association

- Pancreas Club Inc.

- Pancreatic Society of Great Britain and Ireland

- United European Gastroenterology Week

- World Congress of Gastroenterology

In addition, colleagues in the field of surgical and medical gastroenterology were contacted and asked to provide details of outstanding clinical trials or any relevant unpublished materials.

\section{Data collection and analysis}

\section{Selection of studies}

All randomised controlled trials which met the inclusion criteria were retrieved. Two reviewers independently assessed the exclusion of papers identified from the initial searches which were unrelated to pancreatic necrosis in humans. These decisions were based on assessment of at least the title and abstract if available. Decisions on inclusion were also made independently by two reviewers according to the pre-stated eligibility criteria, and recorded on a paper form. It was planned that a third reviewer should review disagreements, but this proved unnecessary.

\section{Data extraction and management}

Data was extracted and recorded onto specially developed forms. Authors were approached when clarification was required for unclear or missing data. Extraction of data was undertaken by two reviewers and checked by a third.

The following characteristics were recorded for each trial: details of the participants including demographic characteristics, source of recruitment, and criteria for diagnosis. Adverse events were noted, especially reports of anti-microbial drug resistance and opportunistic fungal infections. Data were extracted from intention to treat analyses if presented.

\section{Reporting}

Applicability and cost benefit analysis were considered. Comments were to be made on non-RCTs, rejected trials and trials in progress or analysis where appropriate.

\section{Assessment of risk of bias in included studies} Assessment of Study Quality

This was performed by one reviewer and checked by a second. 
Trials meeting the eligibility criteria were assessed for quality according to four characteristics:

- Generation of the allocation schedule: truly random, quasirandom, systematic, not stated/unclear. Computer generated random numbers, coin toss, shuffles, etc were defined as truly random, allocation according to date of birth, patient number, etc are defined as quasi-random, whilst alternate allocation and deterministic methods were classified as systematic.

- Concealment of the treatment allocation: adequate, inadequate, or unclear. If investigators were unaware of each participant's allocation when they are recruited, the allocation was considered to be adequately concealed. Methods such as central randomisation systems or serially numbered opaque envelopes were judged to fit this criterion. If an investigator may have been aware of allocations at recruitment, as when the participant's birth-date or patient number is used for allocation, the allocation was judged inadequate.

- Implementation of masking: (patients' masked, clinicians' masked, outcome assessors' masked). When a placebo was used it was assumed that the participants are masked to their treatment allocation.

- Completeness of follow-up and intention to treat analysis: dropouts and missing data rates by group.

\section{Measures of treatment effect}

Data was entered into RevMan5 by one reviewer and double checked by a second reviewer. Meta-analysis was performed with computation of risk ratios.

\section{Data synthesis}

For outcome measures (death or survival, or other selected event rates), the impact of the intervention was expressed as risk ratios with $95 \%$ confidence intervals. Meta-analysis was only planned to be attempted if there were sufficient trials of similar comparisons reporting the same outcomes. The effect (or lack of effect) of therapy was reported as risk ratios with $95 \%$ confidence intervals.

\section{Subgroup analysis and investigation of heterogeneity \\ Subgroup Analyses}

The data were analysed as comparisons between antibiotic and placebo with conservative management when available. The review protocol originally planned to categorise the data according to the following pre-specified subgroups:

1. the type of antibiotic regimen (i.e. beta-lactam, such as penicillin or cephalosporin based, or quinolone plus imidazole);

2. the time of commencement of therapy in relation to symptom onset and/or hospitalisation, and duration of therapy;

3. aetiology of the attack (attributable to gallstones, alcohol, other identifiable causes, and idiopathic).

Complete data was only found for the type of antibiotic regimen for the previous versions of this review, and therefore the other subgroup analyses have been omitted.

\section{Investigation of heterogeneity}

Significant $(P<0.1)$ heterogeneity was detected in several secondary end-points. As a result possible explanations were investigated informally, and a random effect meta-analysis (instead of a fixed- effect one as in previous versions of this review) was performed for all end-points.

\section{RES U L T S}

\section{Description of studies}

\section{Results of the search}

Since 1975 there have been fourteen reported RCTs which investigated antibiotic prophylaxis in severe acute pancreatitis. No additional RCTs with fully evaluable data were identified from unpublished data sources.

\section{Included studies}

Please see the 'Characteristics of included studies' table for full details. The seven included studies were those published by Pederzoli 1993; Sainio 1995; Nordback 2001; Schwarz 1997 (after translation from German to English by a qualified bi-lingual medical practitioner; Isenmann 2004; Røkke 2007; Dellinger 2007. Two further RCTs have been presented in abstract form and published in Czech language (Spicak 2002; Spicak 2003), but no subgroup of participants with CT proven necrosis has been identified. A further study from the same author has been published in abstract form (Spicak 2004), appears to include from the two previous studies cases in a subgroup of participants with pancreatic necrosis, therefore a decision was taken to await full publication.

\section{Design}

All of the included studies were randomised controlled trials.

\section{Sample sizes}

These seven studies randomised a total of 404 participants with proven pancreatic necrosis, 203 to an antibacterial regimen and 201 to control.

\section{Setting}

The study reported by Røkke (Røkke 2007) was a multicentre, randomised controlled trial conducted in seven hospitals in Norway. The study reported by Dellinger (Dellinger 2007) was an international, multicentre, randomised, placebo-controlled double-blind trial, (carried out in centres from the USA, Belgium, Germany, Spain, and the UK)and evaluated meropenem (a betalactam) as the study drug. Isenmann 2004 included centres across Germany in Ulm, Essen, Magdeburg, Nuremberg, and Heidenheim. The randomised controlled trial from Tampere, Finland, was reported by Nordback 2001; Sainio 1995 was also carried out in Finland (Helsinki). Pederzoli 1993 included six centres in Italy. The non-blinded randomised controlled trial reported by Schwarz (Schwarz 1997) was conducted at Ulm University Surgical Clinic, in Germany.

\section{Participants}

In Pederzoli 1993 a total of 74 participants with severe acute pancreatitis and pancreatic necrosis confirmed on CT were studied between January 1989 and July 1991.

In Sainio 1995 a total of 60 participants were recruited with severe alcohol associated acute pancreatitis, raised $\mathrm{C}$-reactive protein (CRP) of $120 \mathrm{mg} / \mathrm{L}$ or above and pancreatic necrosis proven by CT. The study ran between July 1989 and November 1993. 
In Schwarz 1997, twenty six participants were defined as having severe acute pancreatitis, using CT criteria, from August 1991 to October 1994

Nordback 2001 reported that researchers recruited a total of 58 participants with acute pancreatitis with both pancreatic necrosis on CT and CRP of $150 \mathrm{mg} / \mathrm{L}$ or above during the first 24 hours postadmission to Hospital from September 1995 to May 1999.

The study reported by Isenmann 2004 was originally designed to recruit a sample size of 200 participants so that it would achieve a $90 \%$ power $(\beta)$ to detect a halving of the infection rate from 40 to $20 \%$. After 114 participants were recruited, an interim analysis was performed and recruitment stopped, as the trend in endpoint events ran in the opposite direction of that expected. The study assessed participants within 72 hours of onset of symptoms, and a minimum of a 3-fold elevation of serum amylase or lipase. participants were included if a severe attack was predicted from a CRP exceeding $150 \mathrm{mg} / \mathrm{L}$, or the presence of pancreatic necrosis on CT criteria. The study inclusion criteria attracted criticism (Brown 2004) because, as with the study of Sainio (Sainio 1995), CRP was used for stratification. Brown noted that there is no internationally accepted criterion level or time point for CRP stratification, and it was not included in the Atlanta Classification (Bradley 1993). However as with the study of Sainio, data were easily extracted on participants meeting CT criteria for the diagnosis of pancreatic necrosis for the purposes of the present review.

The study reported by Dellinger (Dellinger 2007) recruited 100 participants, of which 82 had CT proven necrosis at the time of inclusion. Of this subgroup 41 were randomised to treatment and 41 to placebo. A decision was taken to cease recruitment due to funding restrictions, despite a prior calculation that 240 participants were required (120 per group), to ensure adequate power. The primary end-point of the study was to evaluate the effectiveness of prophylactic intravenous meropenem in decreasing the incidence of pancreatic or peripancreatic infection in participants with necrotising pancreatitis, within 42 days following randomisation. Secondary end-points were time between onset of pancreatitis and the development of pancreatic or peripancreatic infection, all-cause mortality, requirement for surgical intervention, and development of non-pancreatic infections within 42 days following randomisation. In order to do that, the investigators searched for participants with proven $C T$ necrosis or, for those participants on which it was not possible to use intravenous contrast due to renal impairment, with $\mathrm{CT}$ findings of Balthazar grade $\mathrm{E}$ (multiple peripancreatic fluid collections and pancreatic oedema) and either a CRP level of more than $120 \mathrm{mg} / \mathrm{L}$ or a multiple organ dysfunction (MOD) score of more than 2 .

In Røkke 2007 A total of 73 participants with symptoms of less than 72 hours duration were recruited. A power calculation estimated that a total of 160 participants would be needed to provide $80 \%$ power $(\beta)$ to demonstrate a halving of infectious complications, from 50 to $25 \%$. Due to slow recruitment the study was closed prior to this total being reached. Inclusion was based on a CRP rising above $120 \mathrm{mg} / \mathrm{l}$ within the first 24 hours, or above $200 \mathrm{mg} / \mathrm{l}$ within 48 hours, or pancreatic necrosis demonstrated on CT.

\section{Interventions}

Five studies (Dellinger 2007; Nordback 2001; Pederzoli 1993; Sainio 1995; Røkke 2007) evaluated a beta-lactam regimen in 302 participants (149 treatment, 153 controls), and two (Isenmann 2004; Schwarz 1997) a quinolone plus imidazole regimen in 102 participants ( 54 treatment, 48 controls).

Pederzoli 1993 allocated forty one participants (mean age 54 years) to the treatment group who received intravenous imipenem/ cilastatin (500mg every eight hours) for 14 days from the time of diagnosis of pancreatic necrosis at CT. Another 33 participants (mean age 50 years) were allocated to the control group. All participants received standard medical (conservative) therapy (nasogastric suction, $\mathrm{H} 2$-blockers, antiprotease drugs, total parenteral nutrition and analgesics).

Thirty of the 60 participants in Sainio 1995 (mean age 43 years) received supportive medical treatment and intravenous $1.5 \mathrm{~g}$ cefuroxime every 8 hours from admission until clinical recovery and normal CRP concentration were achieved; in cases of clinical recovery but moderately raised CRP concentration, oral cefuroxime $250 \mathrm{mg}$ orally 12 hourly was continued for 14 days. The other 30 participants (mean age 38.7 years) received supportive medical treatment, with antibiotics started only when clinically, microbiologically or radiologically indicated, or when there was a secondary rise in the CRP exceeding $20 \%$ after the peak acute phase level.

Thirteen of the 26 participants (mean age 43 years) in Schwarz 1997 received supportive medical treatment plus $200 \mathrm{mg}$ ofloxacin and $500 \mathrm{mg}$ metronidazole twice daily for 10 days. The other 13 participants (mean age 46 years) received supportive medical treatment adding antibiotics only when clinically indicated, or if evidence of infection of the necrotic pancreatic tissue was obtained.

in Nordback 2001 twenty five of fifty eight participants (mean age 47 years) received supportive treatment and $1 \mathrm{~g}$ imipenem with cilastatin intravenously every 8 hours. The point of cessation of prophylactic antibiotics was not defined. A further 33 participants (mean age 46 years) received only supportive treatment. Imipenem with cilastatin was also administered to 14 control participants in whom it was clinically indicated due to consistent increases in inflammatory markers, or after bacteriology positive CT or ultrasonographically guided fine needle aspirate (FNA) from necrotic areas. Nine of those 14 participants responded and avoided the need for surgery, with only 5 participants requiring surgical debridement, which was carried out a minimum of 3 days later.

In Isenmann 2004 participants were randomised to receive $400 \mathrm{mg}$ ciprofloxacin and $500 \mathrm{mg}$ metronidazole intravenously twice daily, or placebo. Study medication was intended to continue for up to 21 days. Of the 114 participants included, 76 were found to have pancreatic necrosis at CT, of which 41 (median age 49.4) received prophylactic antibiotics and 35 (median age 46.5) were controls. Only participants with pancreatic necrosis are included in this review. The study medication was discontinued before day 21 if the participant recovered, or switched to open antibiotics following an operational rule that participants were transferred from blinded treatment to 'open' antibiotic treatment if they continued to deteriorate. This crossover policy reflects clinical practice, but reduces the previously calculated study power. In the subgroup with pancreatic necrosis, 35 of the 76 participants received crossover 'open' antibiotics, which included 15 participants of 41 in 
the antibiotic group (35.6\%), and 20 from 35 in the control group $(57.1 \%)$.

Fifty participants in each group (intervention and control) reported in Dellinger 2007 were randomised to receive intravenously either $1 \mathrm{~g}$ meropenem or placebo every 8 hours. For participants to be included the study it was required that treatment (meropenem or placebo) was commenced within 120 hours of the onset of symptoms. The published study did not include separate data on the subgroup of participants in whom necrosis was detected in CT scanning, except for the endpoint of pancreatic or peripancreatic infection, but this information was kindly provided by Professor Dellinger. This subgroup consisted of 82 patients with CT proven necrosis at the time of inclusion, with 41 receiving antibiotic prophylaxis and 41 placebo. We do not have the mean ages for patients in either arms of this subgroup. They excluded participants who at time of randomisation were diagnosed with pancreatic or peripancreatic infection, or had a course of antibiotics for more than 48 hours prior to randomisation, or who had an allergy to betalactams. Other exclusions included probenecid use, underlying progressing disease and pregnancy.

In Røkke 2007 A total of 73 participants with symptoms of less than 72 hours duration were recruited. Participants were randomised to receive intravenously either $500 \mathrm{mg}$ Imipenem or placebo thrice daily. Participants in either group received antibiotics if infection was diagnosed on clinical, radiological or laboratory criteria. CT or ultrasonographic scan (USS) guided fine-needle aspiration and bacteriological analysis was not routinely employed. Dr Røkke provided unpublished data on 28 participants with CT confirmed necrosis, of which 12 were randomised to imipenem group and 16 to placebo. We do not have the mean ages for patients on either arm of this subgroup.

\section{Outcomes}

Pederzoli 1993 reported a statistically significant decrease in the incidence of infection of pancreatic necrosis (12.2\% versus $30.3 \%)$ and of non-pancreatic infections ( $14.6 \%$ versus $48.5 \%)$, but there were no significant differences in mortality $(7.3 \%$ versus $12.1 \%)$, incidence of MOSF (29.3\% versus $39.4 \%$ ), or number of operations performed $(29.3 \%$ versus $33.3 \%)$.

In Sainio 1995 mortality was significantly lower in the treated group, with 1 death in this group (3.3\%) versus 7 in the placebo group $(23.3 \%)$. It is important to note that two of the deaths that occurred in the control group happened at 2 and 4 days from diagnosis, making it unlikely that infection of the pancreatic necrosis was causal (Beger 1986), although the authors argued that sepsis may have worsened the pre-existing MOSF. The authors concluded that given the low cost and apparent advantages of antibiotic treatment, with an apparent reduction in mortality possibly due to a decrease in the frequency of sepsis, such treatment should be started early in all participants with necrotising pancreatitis.

There was an steady improvement in the clinical condition in the treated group in Schwarz 1997 as demonstrated by a fall in their APACHE II scores from day 1 to day 10 (means of 15 at day 1 and 9.5 at day 10), whereas the APACHE II scores calculated for the placebo group showed a steady increase in the same time period (means of 11.5 at day 1 and 16 at day 10). This was statistically significant (Wilcoxon test, $\mathrm{P}<0.01$ ). None of the participants in the antibiotic group died within the first three weeks, whereas there were 2 deaths in the control group for the same time period. The authors concluded that antibiotic prophylaxis neither prevented nor delayed bacterial infection of the necrotic pancreas, but that antibiotic therapy improved the clinical course when commenced before the onset of clinically obvious infection of the pancreatic necrosis.

The study investigators in Nordback 2001 concluded that, although their findings were not statistically significant, prophylaxis using imipenem with cilastatin therapy appeared to reduce mortality ( $8 \%$ versus $15 \%$ ), need for surgery ( $8 \%$ versus $36 \%$ ), and the overall number of major organ complications ( $28 \%$ versus $76 \%$ ).

The investigators in Isenmann 2004 concluded that no benefit was shown for the use of antibiotic prophylaxis against infection of pancreatic necrosis complicating acute pancreatitis. Given the large number of participants in the antibiotic group who had the initial antibiotics changed, and the large number of patients in the control group that were switched to antibiotic treatment, a bias against treatment benefit could have been introduced, which would have reduced the calculated power of the study (Brown 2004).

The results of Dellinger 2007 did not show a statistical difference between groups of any of the end-points: development of pancreatic or peripancreatic infection (19.5\% treatment versus $12.2 \%$ placebo), mortality ( $14.6 \%$ treatment versus $12.2 \%$ placebo), non-pancreatic infection (31.7\% treatment versus $41.5 \%$ placebo), or need for surgical intervention (24.4\% treatment versus $17.1 \%$ placebo). The investigators concluded that this study did not have sufficient power to reject benefit from the use of antibiotic prophylaxis, but argued that when evaluated alongside previous studies the routine adoption of this measure was not justified. Professor Dellinger provided further information on the 82 participants with CT diagnosed necrosis, which included 41 receiving antibiotic prophylaxis and 41 receiving placebo. Only this subgroup was entered into the present meta-analysis. Most participants received nutritional support, and there was no significant difference in provision between the treatment and the placebo groups.

As stated before, unpublished data provided by Dr Røkke allowed us to identify the 28 participants from his study (Røkke 2007) with CT confirmed necrosis, which included 12 randomised to imipenem group and 16 to placebo. Only this CT confirmed necrosis subgroup is included in this meta-analysis. No statistically significant difference between the groups was found for mortality (16.6\% treatment versus $12.5 \%$ controls), organ failure (data for subgroup with $\mathrm{CT}$ proven necrosis not available), or rates of intervention (16.6\% treatment versus $12.5 \%$ controls). There was however a statistically significant reduction in complications rates and for pancreatic and extrapancreatic infections. There appeared to be a delay in the onset of infection in participants receiving antibiotics, in that no infections were evident before the third week after onset in this group.

\section{Excluded studies}

The three earliest studies were published in the 1970s, and were excluded as at the time CT was not available for the diagnosis of pancreatic necrosis (Finch 1976; Howes 1975; Craig 1975). Of the eleven remaining studies, two further examples were excluded as 
they did not comply with study criteria (Luiten 1995 and Delcenserie 1996). Luiten's study assessed the role of antibacterial prophylaxis combined with selective gastrointestinal tract decontamination. Also, both in this and Delcenserie's studies, participants were selected because they had fluid collections on CT rather than pancreatic necrosis, making them unsuitable for inclusion in this review as $\mathrm{CT}$ data confirming pancreatic necrosis could not be extracted. Please see the 'Characteristics of excluded studies' table.

\section{Risk of bias in included studies}

Please see Figure 1 for a summary of the risk of bias in the included studies.

Figure 1. Methodological quality summary: review authors' judgements about each methodological quality item for each included study.

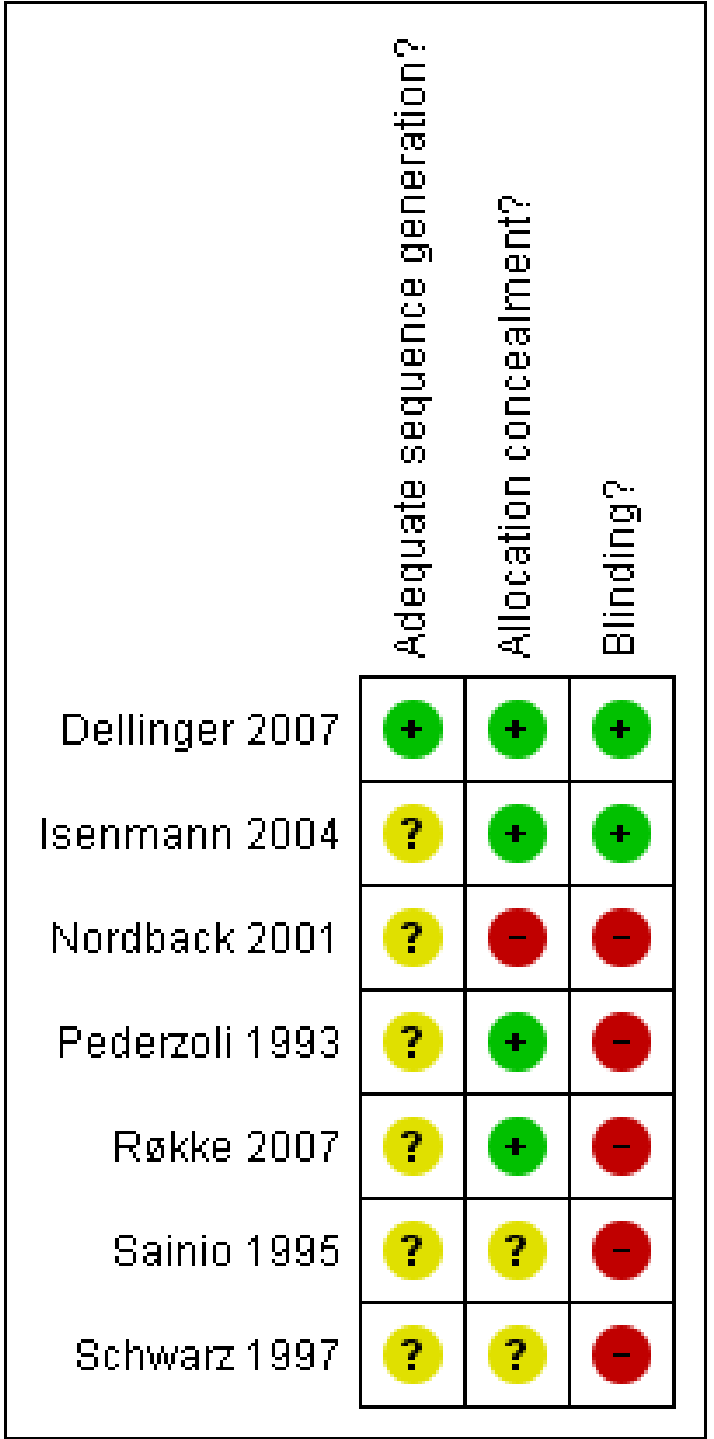

\section{Allocation}

In Pederzoli 1993 and Sainio 1995 the method of randomisation was by casual number table (pre-printed random tables). In Schwarz 1997 and Nordback 2001 the method of randomisation was not stated. Isenmann 2004 randomised by consecutive patient numbers. Røkke 2007 and Dellinger 2007 used computer-based randomisation (without stratification for participating centres in Røkke 2007).

Allocation concealment was adequate in all the trials except Nordback 2001 where allocation concealment was unclear and Røkke 2007 where allocation was inadequate.
The groups were comparable in all the included studies.

\section{Blinding}

Only two studies were double blind; Isenmann 2004 and Dellinger 2007.

\section{Incomplete outcome data}

Outcome data were fully reported in all the included studies. In Pederzoli 1993 there was complete follow-up until death or hospital discharge; in Isenmann 2004 there was complete follow-up until death or hospital discharge. In Røkke 2007 no participants were lost 
or excluded from the analysis, and follow-up in Dellinger 2007 until death or a minimum of 42 days was reported.

\section{Effects of interventions}

The effects of interventions for all studies are detailed below. Subgroup analyses were performed for the type of antibiotic regimen: beta-lactam regimen in 302 participants (149 in treatment and 153 in control groups) (Dellinger 2007; Nordback 2001; Pederzoli 1993; Sainio 1995; Røkke 2007), and a quinolone plus imidazole regimen in 102 participants (54 in treatment and 48 in control groups) (Isenmann 2004; Schwarz 1997). Sub-group analyses could only be performed if data were available for at least two studies in each group. Since there now were 3 studies using the same antibiotic (imipenem), a sub-group analysis for imipenem was also performed including 160 participants (78 in treatment and 82 in control groups).

\section{Antibiotics versus control}

Participants within the studies were of comparable age and gender. Aetiological variations were as expected and in keeping with known geographical and cultural differences.

\section{Mortality}

All cause mortality was evaluable in all seven included studies. Antibacterial prophylaxis was associated a decrease in mortality (8.4\%) versus controls (14.4\%), but this was not significant $(\mathrm{P}=0.07$; $\mathrm{RR} 0.60,95 \% \mathrm{Cl} 0.34$ to 1.05 ) (Analysis 1.1). Most of the survival advantage was contributed by the study of Sainio 1995 (weight $23.9 \%)$.

\section{Infected pancreatic necrosis}

Infected pancreatic necrosis was not significantly different between treatment and placebo groups. Infection occurred in 40 out of 203 participants treated with antibiotics (19.7\%), versus 49 out of 201 controls (24.4\%) ( $\mathrm{P}=0.42 ; \mathrm{RR} 0.85,95 \% \mathrm{Cl} 0.57$ to 1.26 ) (Analysis 1.2 ), with Schwarz 1997 contributing most weight at $26.5 \%$.

\section{Non-pancreatic infections}

Non-pancreatic infection was not evaluable in Sainio 1995 as 'infective events' rather than individual participants affected were reported. Non-pancreatic infections were not reported at all in Schwarz 1997. Therefore these two studies could not be included in the analysis of non-pancreatic infection. In the remaining five studies, there were less episodes in antibiotic treated participants (38 of $160,23.7 \%$ ) versus controls (57 of $158,36 \%$ ), but this difference was not statistically significant $(P=0.08$; RR $0.62,95 \% \mathrm{Cl}$ 0.36 to 1.06 ) (Analysis 1.3).

\section{All sites infections}

As the incidence of non-pancreatic infections could not be evaluated in either the Sainio 1995 or the Schwarz 1997 studies, they were not included in the analysis of all site infections, that is, the total incidence of both pancreatic and non-pancreatic infections. All sites infection episodes were less common in the antibiotic group (60 out of $160,37.5 \%$ ) than in controls (82 out of $158,51.9 \%$ ), but this difference was not statistically significant $(\mathrm{P}=0.12$; RR 0.69, 95\% $\mathrm{Cl} 0.44$ to 1.09 ) (Analysis 1.4).

\section{Resistant organisms}

Only Isenmann 2004 and Dellinger 2007 reported on infection with resistant organisms. In Isenmann 2004, the authors reported a significant increase of infection by ciprofloxacin resistant organisms in the antibiotic group, ciprofloxacin being the antibacterial agent used in this study $(P<0.0001)$. In Dellinger 2007 there were 5 bacterial isolates resistant to meropenem in the treatment group (4 pancreatic and 1 non-pancreatic infections), and 5 in controls ( 2 pancreatic and 3 non-pancreatic infections). Neither study provided details as to whether isolates belonged to individual participants, or which organisms were cultured.

\section{Fungal infections}

Fungal infections were evaluable in all studies, and were not significantly increased in the antibiotic treated group, with an incidence of 8 out of 203 (3.9\%) treated participants versus 10 out of 201 controls (5\%) ( $\mathrm{P}=0.91$; RR $1.06,95 \% \mathrm{Cl} 0.41$ to 2.70 ) (Analysis 1.5). Schwarz 1997 contributed most weight at $33.9 \%$.

\section{Operative treatment}

Operative treatment rates were unavailable for the study of Schwarz 1997. In the remaining six studies there were no significant differences between participants treated with antibiotics (43 of 190, $22.6 \%$ ) versus controls ( 45 of $188,24 \%)(P=0.58$; RR $0.90,95 \% \mathrm{Cl} 0.62$ to 1.31) (Analysis 1.6).

\section{Beta-lactam versus control}

\section{Mortality}

In studies using beta-lactam prophylaxis, treatment was associated with fewer deaths at $9.4 \%$ versus controls $15 \%$, but this was not statistically significant ( $P=0.33$; RR $0.72,95 \% \mathrm{Cl} 0.37$ to 1.40 ) (Analysis 2.1).

\section{Infected pancreatic necrosis}

Rates of infection of pancreatic necrosis were less frequent, but not significantly so, with treatment at $16.8 \%$ versus $24.2 \%$ in controls ( $\mathrm{P}=0.19$; RR $0.69,95 \% \mathrm{Cl} 0.40$ to 1.19 ) (Analysis 2.2).

\section{Non-pancreatic infections}

There was a non-significant trend towards lower incidence of non-pancreatic infections of $21 \%$ in the treatment group, versus $32.5 \%$ in the control group $(\mathrm{P}=0.29$; RR $0.64,95 \% \mathrm{Cl} 0.28$ to 1.47) (Analysis 2.3); but this endpoint included only four studies (Dellinger 2007; Pederzoli 1993; Nordback 2001; Røkke 2007), as Sainio's study (Sainio 1995) reported infective events rather than individual participants affected, as mentioned earlier.

\section{All sites infections}

Overall infections were non-significantly lower in this subgroup with an incidence of $34.4 \%$ in those treated versus $52.8 \%$ in the control group ( $\mathrm{P}=0.12$; $\mathrm{RR} 0.63 ; 95 \% \mathrm{Cl} 0.35$ to 1.13 ) (Analysis 2.4), and this included the same four studies as described for nonpancreatic infections (Pederzoli 1993; Nordback 2001; Røkke 2007; Dellinger 2007).

\section{Fungal infections and operative rates}

There were no significant differences in operative rates or fungal infection rates (Analysis 2.5; Analysis 2.6). 


\section{Quinolone versus control}

\section{Mortality}

In studies of quinolone plus imidazole prophylaxis, there was no significant difference in mortality at $5.5 \%$ with treatment versus $12.5 \%$ in controls $(\mathrm{P}=0.31$; $\mathrm{RR} 0.51,95 \% \mathrm{Cl} 0.14$ to 1.85 ) (Analysis 3.1).

\section{Infected pancreatic necrosis}

Rates of pancreatic sepsis were not significantly different between treatment groups at $27.8 \%$ versus $25 \%$ in controls $(P=0.61 ; R R 1.16$, $95 \% \mathrm{Cl} 0.66$ to 2.03 ) (Analysis 3.2).

\section{Non-pancreatic infections and all sites infections}

Only one study (Isenmann 2004) reported on extra-pancreatic infections, with Schwarz 1997 reporting on infective events instead, and therefore a subgroup analysis could not be performed in either this category or in overall pancreatic infections.

\section{Fungal infections}

There was no significant difference in fungal infection rates, at $7.4 \%$ for treatment versus $6.2 \%$ in controls $(P=0.71$; RR $1.30,95 \% \mathrm{Cl} 0.32$ to 5.21) (Analysis 3.3).

\section{Operative treatment}

Operation rates were only available in one study (Isenmann 2004) (data not shown).

\section{Imipenem versus control}

\section{Mortality}

Although not originally planned as a formal sub-group analysis, it was noted that when the studies evaluating imipenem plus cilastatin versus control (Pederzoli 1993; Nordback 2001; Røkke 2007) are considered separately, there was no significant reduction of mortality associated with treatment $(9 \%)$ versus control $(13.4 \%)$ $(\mathrm{P}=0.45$; RR $0.70,95 \% \mathrm{Cl} 0.28$ to 1.75 ) (Analysis 4.1),

\section{Infected pancreatic necrosis}

There were significant reductions in rates of infection of pancreatic necrosis (10.2\% versus $24.4 \%$ ) ( $P=0.02 ; \mathrm{RR} 0.34,95 \% \mathrm{Cl} 0.13$ to 0.84 ) (Analysis 4.2)

\section{Non-pancreatic infections and all sites infections}

There were significant reductions in rates of infections overall (25.6\% versus $52.4 \%$ ) ( $\mathrm{P}=0.01 ; \mathrm{RR} 0.49 ; 95 \% \mathrm{Cl} 0.28$ to 0.87 ) (Analysis 4.4 ), but in this subgroup there were no significant differences in rates of non-pancreatic infections ( $15.4 \%$ versus $28 \%)(P=0.58$; $R R$ $0.67,95 \% \mathrm{Cl} 0.16$ to 2.77 ; Analysis 4.3 )

\section{Fungal infections and operative treatment}

There were no significant differences in rates of fungal infection (Analysis 4.5) or rates of operation (Analysis 4.6) in each group.

\section{Other analyses}

Other sub-group analyses planned in the protocol, but not performed include:

1. the time of commencement of therapy in relation to symptom onset and hospitalisation, and duration of therapy. This was due to lack of reported data on commencement and variability in duration of treatment. One study (Røkke 2007) employed antibiotic prophylaxis for 5 to 7 days, another (Schwarz 1997) adopted a treatment duration of 10 days, with another (Isenmann 2004) study permitting up to 21 days therapy. The four remaining studies (Dellinger 2007; Nordback 2001; Pederzoli 1993; Sainio 1995; ) set a treatment duration of 14 days, but with varying stopping criteria;

2. aetiology of the attack: a sub-analysis for attacks attributed to gallstones, alcohol, other identifiable causes, and idiopathic was planned. Although data were provided for aetiology of the whole study group at inclusion, no study provided sufficient data to enable outcomes to be analysed by aetiology.

\section{DISCUSSION}

\section{Summary of main results}

A previous version of this review published in 2006 (Villatoro 2006) which evaluated 5 studies, compared with 7 in the current review, suggested a significant survival advantage for the antibiotic treated group. In addition, within the subgroup treated with a beta-lactam, also significantly decreased rates for infection of pancreatic necrosis, in contrast to quinolone plus imidazole regimens with were not associated with any significant differences in outcome. Since that review two further RCTs, one double-blinded (Dellinger 2007) and the other unblinded (Røkke 2007), have been published and met the criteria for inclusion. Following the addition of these two RCTs, although there remains a trend towards lower mortality after antibiotic therapy, meta-analysis no longer demonstrates the significant survival advantage demonstrated in the previous version of this review (Villatoro 2006). However, there are significantly lower rates for non-pancreatic infections. There were also persisting trends towards decreased rates of pancreatic infection and operative debridement associated with antibiotic treatment, but there were no significant differences. Although the hypothesis underpinning each RCT was that antibiotic prophylaxis could prevent pancreatic infection, it appears possible that any positive treatment effect may be an effect of reduced rates of non-pancreatic sepsis, such as serious pulmonary infections. Røkke (Røkke 2007) postulated that reducing the risk of serious non-pancreatic infection might beneficially delay the onset of pancreatic infection. However there was some heterogeneity between RCTs in the analysis of non-pancreatic infections, and this may be a result of the lack of classification of non-pancreatic infections specified within the Atlanta (Bradley 1993) or Santorini (Dervenis 1999) criteria. Data for antimicrobial resistance were only available from two studies (Dellinger 2007; Isenmann 2004), and none of the seven studies provided data concerning aetiology in relation to outcome. There was no significant difference in the rates of fungal infection between groups, although the overall incidence was low at 4.5\%, compared with published reports (Grewe 1999; Gloor 2001; De Waele 2003). Fungal infections are more difficult to detect than bacterial infections. Sub-group analyses suggested that different treatment regimens may provide different results: betalactam treatment appears to produce a greater treatment effect than quinolone/imidazole combinations. The reduced numbers of participants in the sub-group analyses may mask other genuine differential treatment effects. 


\section{Overall completeness and applicability of evidence}

The results of the present review show only a trend towards improved survival and infection rates for pancreatic necrosis after antibiotic prophylaxis, but there was significant reduction of nonpancreatic infection. This may be explained due to a therapeutic effect on, for example, serious pulmonary infections, with are relatively common secondary events in patients with severe acute pancreatitis and acute respiratory distress syndrome. However this view is not supported by data, as specific infections were not detailed in any of the studies reviewed.

Examining subgroups receiving prophylaxis with a beta-lactam ( Dellinger 2007; Nordback 2001; Pederzoli 1993; Sainio 1995; Røkke 2007) versus quinolone and imidazole combinations (Isenmann 2004; Schwarz 1997), significantly decreased non-pancreatic infection was confirmed for the former but not the latter, where the trend reversed towards worsened survival. When evaluating all sites infection, that is, both pancreatic and non-pancreatic infections, the beta-lactam subgroup retains a significant reduction of infection, but such analysis could not be done in the quinolone and imidazole combination group since only data from one study was available for analysis (Isenmann 2004).

It is difficult to conduct a cost benefit analysis for the prophylaxis of superinfection in pancreatic necrosis, as the costs of the drugs vary, as does the cost provision of critical care therapy and surgery. The UK National Health Service Economic Evaluation Database (NHS EED, Cochrane Library) identifies four studies in which the title suggested that cost-effectiveness was covered, but none were abstracted as they covered only costs rather than balancing these with the effect of benefits. A study of patients operated upon in the early 1990s for infected pancreatic necrosis in Glasgow, Scotland, estimated an average cost at $£ 18,441$ with a range extending up to $£ 34,000$ (Fenton-Lee 1993). The management of patients with infected necrosis often requires repeated visits to the operating theatre, multiple CT scans, and weeks or months in critical care areas. There appeared to be no significant reduction in operative rates despite reduced superinfection and mortality rates - a factor which suggests a need for larger studies or more strict management protocols. Røkke's study (Røkke 2007) warned that the reduction of septic episodes and delayed onset of infection of necrosis observed in the treatment arm of his RCT came at a cost double that of the control group, which was not felt to be cost effective as there was no significantly decreased mortality nor surgical interventions rates.

Representative, contemporary costs of treatment regimes in the UK were analysed using the 57th edition of the British National Formulary (http://www.bnf.org.uk). The most expensive agent evaluated in the present review was meropenem (Dellinger 2007) which at $1 \mathrm{~g}$ thrice daily costs $£ 85.95$ per day, followed by imipenem with cilastatin (Nordback 2001) which at 1 g thrice daily costs $£ 72$ per day, ciprofloxacin $400 \mathrm{mg}$ and metronidazole $500 \mathrm{mg}$ twice daily (Isenmann 2004) at $£ 50.82$ p daily (ciprofloxacin $£ 44$, metronidazole $£ 6.82 \mathrm{p}$ ), then ofloxacin $200 \mathrm{mg}$ plus metronidazole $500 \mathrm{mg}$ twice daily (Schwarz 1997) at $£ 40.46 \mathrm{p}$ daily (ofloxacin $£ 33.64 p$, metronidazole $£ 6.82 p$ ), imipenem with cilastatin at $500 \mathrm{mg}$ three times a day (Pederzoli 1993; Røkke 2007) at $£ 36$ per day, with the least expensive regimen being cefuroxime $1.5 \mathrm{~g}$ three times a day (Sainio 1995) at $£ 14.10$ per day, costing $16 \%$ of the most expensive.

\section{Quality of the evidence}

A major concern over the quality of design and execution of the RCTs reviewed remains. However they extend over a long time period, and whilst earlier studies reflected a state of the art approach at the time they were conducted, it is only relatively recently that two double-blinded studies have been carried out. Any future studies would now be expected to follow this approach. Although it is accepted that there are difficulties in meeting predicted sample sizes, future studies should be properly resourced so that funding restraints do not play a part in decisions to cease a study on the basis of interim results (Werner 2007).

\section{Potential biases in the review process}

None known.

\section{Agreements and disagreements with other studies or reviews}

A previous meta-analysis examined eight prospective RCTs of antibiotic prophylaxis in acute pancreatitis (Golub 1998), but studies were not selected on the basis of inclusion with pancreatic necrosis proven on $\mathrm{CT}$, and mortality was the only end-point analysed. A large variety of sub-analyses involving different combinations of studies was carried out, including one focussing on four studies evaluating broad spectrum antibiotics (Delcenserie 1996; Pederzoli 1993; Sainio 1995; Schwarz 1997). This subgroup was associated with significantly reduced mortality in antibiotic treated patients $(5.3 \%)$ compared to controls $(18.2 \%)$, odds ratio $0.25(95 \% \mathrm{Cl} 0.09,0.72)$. The authors concluded that patients with severe pancreatitis by an Imrie or Ranson score of 3 and above, or apparently severe disease at $\mathrm{CT}$, should receive broadspectrum antibiotics such as imipenem or a fluoroquinolone. However this review did not include the four more recent studies reviewed here (Dellinger 2007; Isenmann 2004; Nordback 2001; Røkke 2007) of higher quality, since they were published later. DARE-CRD reviewers (CRD database: DARE-994541) commented on the variable methodological quality of this meta-analysis, and cautioned that the conclusions should be interpreted cautiously due to the small number of studies included.

A similar review of antibiotic effectiveness in acute pancreatitis published in 1999 (Kramer 1999) adopted a diagnostic amylase level for inclusion rather than using the Atlanta criteria. This review excluded three studies conducted before $\mathrm{CT}$ had become available for the diagnosis of pancreatic necrosis, but included one retrospective review. The authors concluded that antibiotics should be administered to patients with severe disease predicted by a Ranson score of 3 or above, and two or more acute fluid collections or necrosis involving one third or more of the pancreas at CT. However, the review was a narrative and no formal meta-analysis was performed. DARE-CRD reviewers (CRD database number: DARE-991015) commented that the aim was not clearly stated, inclusion criteria were broad, studies were restricted to those published in English, and conclusions were not strongly supported by the evidence presented. Again, this review did not include four later studies analysed in the present review (Dellinger 2007; Nordback 2001; Isenmann 2004; Røkke 2007).

Three further reviews have been published since the last edition of the present review (Heinrich 2006; Mazaki 2006; De Vries 2007). 
Heinrich's review (Heinrich 2006) focused on evidence-based management of acute pancreatitis in general. In the analysis of antibiotic prophylaxis, five studies (Isenmann 2004; Nordback 2001; Pederzoli 1993; Sainio 1995; Schwarz 1997) were considered, identical to those in the previous version of the present review. Additional data was provided for the subgroup of patients with pancreatic necrosis shown by CT in Isenmann's study after personal communication with the authors. However the data analysed appeared to differ markedly from that published in the number of patients with proven necrosis in the treatment and control groups, perhaps because they included those found to have necrosis both at operation and CT. The authors decided to exclude this study (Isenmann 2004) from the mortality analysis, claiming that this study lacked uniformity in the treatment of infected necrosis. Their recommendation was that antibiotic prophylaxis should be routinely adopted for pancreatic necrosis, but this may be skewed by the exclusion of Isenmann's study. The management of pancreatic necrosis in Isenmann's study reflected the diversity of clinical practice, and there was at the time, as now, no rigid protocol available.

A meta-analysis published by Mazaki 2006 included the same studies (Isenmann 2004; Nordback 2001; Pederzoli 1993; Sainio 1995; Schwarz 1997) as the review of Heinrich 2006, and the previous version of the current review (Villatoro 2006), with the addition of a further study (Spicak 2004). The additional study was published only in abstract form and appears to contain a mix of patients from two previously published studies (Spicak 2002; Spicak 2003). As previously mentioned, in the absence of a full publication and a lack of response to enquiries for data clarification, the study was excluded from the present review. The conclusion reached by the authors was that antibiotic prophylaxis was not associated with significant differences in mortality, rates of infected necrosis, or non-pancreatic infection, but antibiotic therapy was associated with a significantly reduced length of hospitalisation in the antibiotic group compared to controls (I-V fixed weighted mean difference, $-5.64 ; 95 \% \mathrm{Cl},-11.0$ to -0.27 ; $\mathrm{P}$ $=0.04$ ), but they could only extract this data from three of the six studies included (Nordback 2001; Sainio 1995; Spicak 2004).

One further review (De Vries 2007) included only studies that reached a methodological quality threshold from a set of nonvalidated criteria which assessed the study population, type of intervention, and the participant flow. This led to the exclusion of both Spicak's earlier published studies (Spicak 2002; Spicak 2003). They also excluded Nordback 2001, because they judged that antibiotic prophylaxis was used in both arms of the study. In fact, Nordback's study adopted the same approach as other studies in that ethically, antibiotics could not be withheld once clinically indicated. The target group for this analysis was severe acute pancreatitis rather than CT proven necrosis, thus Delcenserie 1996 was included because of the presence of collections at $\mathrm{CT}$ rather than pancreatic necrosis, as were raw published data from Isenmann's and Dellinger's studies (Isenmann 2004; Dellinger 2007), rather than restricting extraction to patients with proven necrosis at CT. Accordingly the authors concluded that antibiotic prophylaxis in severe acute pancreatitis does not prevent deaths or infection of pancreatic necrosis. As not every patient with severe acute pancreatitis suffers from pancreatic necrosis, the conclusion is inappropriate in determining whether antibiotic prophylaxis prevents infection of confirmed pancreatic necrosis.

\section{AUTHORS' CONCLUSIONS}

\section{Implications for practice}

This meta-analysis assessed the efficacy of antibiotic prophylaxis against infection within a population of subjects proven to be suffering from established pancreatic necrosis. The inclusion of patients with severe acute pancreatitis, many of whom would not be harbouring pancreatic necrosis would have reduced the potential to confirm therapeutic benefit. The addition of greater numbers of patients from a further two RCTs has led to an alteration of the conclusions from the previously published version of this review (Villatoro 2006). Although there remains a trend towards increased survival and reduced rates of infection of pancreatic necrosis, this is no longer statistically significant. Secondary endpoints also show a trend towards less incidence of nonpancreatic infections and all sites infections, perhaps conferring a non-statistically significant tilt in the balance towards a protective effect in this group of severely unwell patients. One study was interpreted by its authors as suggesting a beneficial delay in the onset of infection, such as to occur after the first inflammatory phase of the attack, thus lessening its effect and making any surgical intervention safer since the necrosis would have had time to mature (Røkke 2007); unfortunately no other study provided data to support such a concept.

Although a variety of antibacterial agents and regimens were utilised in the studies evaluated, they are classified in two main groups. From subgroup analysis it appears that beta-lactam agents, particularly imipenem, rather than quinolone plus imidazole combinations were most likely to provide therapeutic benefit, although it should be stressed that there was no significant reduction in mortality or rates of infection for the beta-lactam group as a whole, but only a significant reduction of infection of the necrosis for the imipenem group. If further studies were to be undertaken, then a beta-lactam based regimen would appear to be the most appropriate choice.

Despite widely held misgivings by clinicians about adverse effects, no significant risk of adverse effects from antibiotic prophylaxis was detected, although data on resistance to routinely available antibacterial agents was restricted to only two studies (Dellinger 2007; Isenmann 2004). The low reported incidence of fungal infection requires further investigation, as it is at variance with that reported in other published studies (Grewe 1999; Gloor 2001; De Waele 2003).

Available guidelines are vague on the role of antibiotic prophylaxis in this setting, reflecting the quality of the underlying evidence. Current UK guidelines (Johnson 2005), suggest that if prophylactic antibiotics are used these should be continued for a duration of 7 to 14 days, considering local prescribing costs. In the present review the RCTs included varied too widely with respect to treatment duration and treatment cessation rules for any meaningful analysis to be undertaken.

An important message from the current review is that, to achieve the maximum probability of demonstrating a therapeutic effect, studies should be restricted wholly to patients in who pancreatic necrosis has been proven by $C T$ criteria. CT is now widely available and can be carried out early in the admission, when it is unusual for acute renal failure to be so established as to contraindicate intravenous contrast administration. It is logical to employ a 
prognostic system such as Ranson, Glasgow, or APACHE-II scores (Bradley 1993; Dervenis 1999), or CRP levels to increase the proportion of patients screened for entry into an RCT. However the use of these criteria alone as a proxy for the presence of pancreatic necrosis is unwise, as the yield is far from perfect and it is illogical to evaluate a treatment regimen for its effect on a condition that study subjects are not suffering from.

In summary, despite persisting trends of therapeutic benefit, the addition of more recent, higher quality RCTs leads us to recommend only that further research is needed. The only statistically significant benefit observed was in the reduction of infection of the pancreatic necrosis in the imipenem subgroup, which may be of value but was not associated with any significant effect on overall mortality. It is in the nature of studies of events with low frequency end-points that individual studies are consistently underpowered. Until further RCTs are carried out, the data from the present meta-analysis does not support routine prescribing of antibiotic prophylaxis in established pancreatic necrosis complicating acute pancreatitis.

\section{Implications for research}

A firm recommendation of the review is that further high quality, double-blinded placebo-controlled RCTs are required to examine the significance of trends towards positive therapeutic benefit. Trial design should also consider the duration of therapy and adopt consistent stopping rules. Sample size and therefore statistical power must take account of the ethical use of the need to 'crossover' to active, non-trial treatment, should antibiotic treatment become mandatory as part of the management of established sepsis. Greater detail should be obtained on the outcome of attacks of varying aetiology. More accurate definitions should be provided for non-pancreatic infections, and a clear distinction must be drawn between infected pancreatic necrosis and infected peripancreatic fluid collections (Beger 1986; Fedorak 1992). Adequate data should also be sought on adverse effects, such as the induction of bacterial resistance and the development of opportunistic fungal infection.

\section{ACKNOWLEDGEMENTS}

The authors thank Janet Lilleyman, Iris Gordon, Cathy Bennett, and Professor David Forman of the Cochrane Upper GI and Pancreatic Diseases group for their assistance and encouragement with the initial review, previous and current revisions. We also acknowledge the contribution of Professor Claudio Bassi for developing the original protocol, and for his contribution to the continuing debate having been involved in original research in this topic area.

We are very grateful to Dr Franz Schattka, Consultant Urological Surgeon, for undertaking the translation of the paper by Schwarz and colleagues (Schwarz 1997) from German to English.

We thank the principal authors of included RCTs who kindly responded to our enquiries and provided additional data required: Dr Isto Nordback (Nordback 2001), Dr Ola Røkke (Røkke 2007), and Professor E Patchen Dellinger (Dellinger 2007). 


\section{RE F E R E N C E S}

\section{References to studies included in this review}

Dellinger 2007 \{published and unpublished data\}

* Dellinger EP, Tellado JM, Soto NE, Ashley SW, Barie PS, Dugernier T, Imrie CW, Johnson CD, Knaebel HP, Laterre PF, Maravi-Poma E, Olsina-Kissler JJ, Sanchez-Garcia M, Utzolino S. Early antibiotic treatment for severe Acute Necrotizing Pancreatitis: a randomized, double-blind, placebo-controlled study. Annals of Surgery 2007;245(5):674-83.

\section{Isenmann 2004 \{published data only\}}

* Isenmann R, Rünzi M, Kron M, Kahl S, Kraus D, Jung N, Maier L, Malfertheiner P, Goebell H, Beger HG. Prophylactic antibiotic treatment in patients with predicted severe acute pancreatitis: a placebo-controlled, double-blind trial. Gastroenterology 2004;126:997-1004.

\section{Nordback 2001 \{published and unpublished data\}}

* Nordback I, Sand J, Rauni S, Paajanen H. Early treatment with antibiotics reduces the need for surgery in acute necrotizing pancreatitis - A single-center randomized study. Journal of Gastrointestinal Surgery 2001;5:113-120.

\section{Pederzoli 1993 \{published data only\}}

* Pederzoli P, Bassi C, Vesentini S, Campedelli A. A randomized multicenter clinical trial of antibiotic prophylaxis of septic complications in acute necrotizing pancreatitis with imipenem. Surgery, Gynecology \& Obstetrics 1993;176:480-3.

Røkke 2007 \{published and unpublished data\}

* Røkke O, Harbitz TB, Liljedal J, Pettersen T, Fetvedt T, Heen LO, Skreden K, Viste A. Early treatment of severe pancreatitis with imipenem: A prospective randomized clinical trial. Scandinavian Journal of Gastroenterology 2007;42:771-6.

Sainio 1995 \{published data only\}

* Sainio V, Kemppainen E, Puolakkainen P, Taavitsainen M, Kivisaari L, Valtonen V, Haapiainen R, Schröder T. Early antibiotic treatment in acute necrotising pancreatitis. The Lancet 1995;346:663-7.

\section{Schwarz 1997 \{published data only\}}

* Schwarz M, Isenmann R, Meyer H, Beger HG. Antibiotics in necrotizing pancreatitis. Results of a controlled study. [Antibiotika bei nekrotisierender Pankreatitis]. Dtsch med Wschr 1997;122:356-61.

\section{References to studies excluded from this review}

Bassi 1998 \{published data only\}

Bassi C, Falconi M, Talamini G, Uomo G, Papaccio G, Dervenis C, Salvia R, Bertazzoni Minelli E, Pederzoli P. Controlled clinical trial of Pefloxacin versus Imipenem in severe acute pancreatitis. Gastroenterology 1998;115:1513-7.

Craig 1975 \{published data only\}

* Craig RM, Dordal E, Myles L. The use of ampicillin in acute pancreatitis. Annals of Internal Medicine 1975;83:831-2.
Delcenserie 1996 \{published data only\}

* Delcenserie R, Yzet T, Ducroix JP. Prophylactic antibiotics in treatment of severe acute alcoholic pancreatitis. Pancreas 1996;13(2):198-201.

Finch 1976 \{published data only\}

* Finch WT, Sawyers JL, Shenker S. A prospective study to determine the efficacy of antibiotics in acute pancreatitis. Annals of Surgery 1976;183:667-71.

Gelfand 2001 \{published data only\}

* Gelfand BR, Burnevich SZ, Gelfand EB, Tsydenzhapov ETs, Bryukhov AN, Brazhnik TB, Saganov VP, Pukhaev DA. Efficacy of pefloxacin (Abactal) in the complex treatment of patients with pancreatonecrosis. Antibiot Khimioter 2001;46(5):24-7.

Howes 1975 \{published data only\}

* Howes R, Zuidema GD, Cameron JL. Evaluation of prophylactic antibiotics in acute pancreatitis. Journal of Surgical Research 1975;18:197-200.

Imaizumi 2004 \{published data only\}

* Imaizumi H, Kida M, Nishimaki H, Okuno J, Kataoka Y, Kida Y, Soma K, Saigenji K. Efficacy of continuous regional arterial infusion of a protease inhibitor and antibiotic for severe acute pancreatitis in patients admitted to an intensive care unit. Pancreas 2004;28:369-73.

\section{Luiten 1995 \{published data only\}}

* Luiten EJT, Hop WCJ, Lange JF, Bruining HA. Controlled clinical trial of selective decontamination for the treatment of severe acute pancreatitis. Annals of Surgery 1995;222(1):57-65.

Manes 2006 \{published data only\}

* Manes G, Uomo I, Menchise A, Rabitti PG, Ferrara EC, Uomo G. Timing of antibiotic prophylaxis in acute pancreatitis: a controlled randomised study with meropenem. American Journal of Gastroenterology 2006;101:1348-53.

Maravi-Poma 2003 \{published data only\}

* Maravi-Poma E, Gener J, Alvarez-Lerma F, Olaechea P, Blanco A, Dominguez-Muñoz JE. Early antibiotic treatment (prophylaxis) of septic complications in severe acute pancreatitis: a prospective, randomized, multicenter study comparing two regimens with imipenem-cilastatin. Intensive Care Medicine 2003;29:1974-80.

Takeda 1996 \{published data only\}

* Takeda K, Matsuno S, Sunamura M, Kakugawa Y. Continous regional arterial infusion of protease inhibitor and antibiotics in acute necrotizing pancreatitis. American Journal of Surgery 1996;171:394-8.

\section{References to studies awaiting assessment}

Barreda 2009 \{published data only\}

Barreda L, Targarona J, Milian W, Portugal J, Sequeiros J, Pando E, Calisto JL. Is the prophylactic antibiotic therapy with 
imipenem effective for patients with pancreatic necrosis? [ $i$ Es la antibióticoterapia profiláctica con imipenem efectiva en los pacientes con necrosis pancreática?]. Acta Gastroenterológica Latinoamericana March 2009;39(1):24-9.

García-Barrasa 2009 \{published data only\}

García-Barrasa A, Borobia FG, Pallares R, Jorba R, Poves I, Busquets J, Fabregat J. A double-blind, placebo-controlled trial of ciprofloxacin prophylaxis in patients with acute necrotizing pancreatitis. J Gastrointest Surg 2009;13:768-74.

Spicak 2002 \{published data only\}

* Spicak J, Hubaczova M, Antos F, Bartova J, Cech P, Kasalicky M, Kostka R, lata J, Leffler J, Zavoral M. Antibiotics in the treatment of acute pancreatitis - findings from a randomized multi-centre prospective study [(Czeck)]. Ceska a Slovenska Gastroenterologie a Hepatologie 2002;56(5):183-9.

\section{Spicak 2003 \{published data only\}}

* Spicak J, Hejtmankova S, Cech P, Hoskovec D, Kostka R, Leffler J, et al. Antibiotic prophylaxis in Severe acute Pancreatitis: Randomized Multicenter Prospective Trial with Meropenem. Ceska a Slovenska Gastroenterologie a Hepatologie 2003;57(6):228-232.

\section{Spicak 2004 \{published data only\}}

Spicak J, Hejtmankova S, Cech P, Hoskovec D, Kostka R, Leffler J. Antibiotics prophylaxis in large pancreatic necrosis: multicenter randomized trial with ciprofloxacin and metronidazole or meropenem. Gastroenterology 2004;126 (suppl 2):A-229. [Abstract S1497]

Xue 2009 \{published data only\}

Xue P, Deng LH, Zhang ZD, Yang XN, Wan MH, Song B, Xia Q. Effect of antibiotic prophylaxis on acute necrotizing pancreatitis: Results of a randomized controlled trial. Journal of Gastroenterology and Hepatology 2009;24:736-42.

\section{Additional references}

\section{Ammori 1999}

Ammori BJ, Leeder PC, King RF, Barclay GR, Martin IG, Larvin M, McMahon MJ. Early increase in intestinal permeability in patients with severe acute pancreatitis: correlation with endotoxemia, organ failure, and mortality. Journal of Gastrointestinal Surgery 1999;3(3):252-62. [PMID: 10481118]

\section{Barie 1996}

Barie PS. A critical review of antibiotic prophylaxis in severe acute pancreatitis. American Journal of Surgery 1996;172(6A):38S-43S.

\section{Bassi 1994a}

Bassi C. Infected pancreatic necrosis. International Journal of Pancreatology 1994;16(1):1-10.

\section{Bassi 1994b}

Bassi C, Pederzoli P, Vesentini S, Falconi M, Bonora A, Abbas H, Benini A, Bertazzoni EM. Behaviour of antibiotics during human necrotising pancreatitis. Antimicrobial Agents and Chemotherapy 1994;38(4):830-6.

\section{Beger 1986}

Beger HG, Bittner R, Block S, Buchler M. Bacterial contamination of pancreatic necrosis: a prospective clinical study. Gastroenterology 1986;91(2):433-8. [MEDLINE: 86248522]

\section{Bertazzoni 1996}

Bertazzoni Minelli E, Benini A, Muner A, Bassi C, Abbas H, Pederzoli P. Pefloxacin penetration into human necrotic pancreatic tissue. Journal of antimicrobial chemotherapy 1996;38:237-43.

\section{Bradley 1989}

Bradley EL. Antibiotics in acute pancreatitis. Current status and future directions. American Journal of Surgery 1989;158(5):472-8.

\section{Bradley 1993}

Bradley EL. A clinically based classification system for acute pancreatitis: Summary of the International Symposium on Acute Pancreatitis, Atlanta, Ga, September 11 through 13, 1992. Archives of Surgery 1993;128(5):586-90.

\section{Bradley 1999}

Bradley III EL. Necrotizing pancreatitis. British Journal of Surgery 1999;86:147-8.

\section{Brown 2004}

Brown A. Prophylactic antibiotic use in severe acute pancreatitis: hemlock, help, or hype?. Gastroenterology 2004;126(4):1195-8.

\section{Burns 1986}

Burns GP, Stein TA, Kabnick LS. Blood-pancreatic juice barrier to antibiotic excretion. The American Journal of Surgery 1986;151:205-8.

\section{Büchler 1992}

Büchler M, Malfertheiner P, Friess $\mathrm{H}$, Isenmann R, Vanek E, Grimm H, Schlegel P, Friess T, Beger HG. Human pancreatic tissue concentration of bactericidal antibiotics. Gastroenterology 1992;103(6):1902-8.

Büchler 2000

Büchler MW, Gloor B, Müller CA, Friess H, Uhl W. Acute necrotizing pancreatitis: treatment strategy according to the status of infection. Ann Surg 2000;232(5):627-9. [MEDLINE: 11066131]

\section{Connor 2004}

Connor S, Alexakis N, Neal T, Raraty M, Ghaneh P, Evans J, Hughes M, Rowlands P, Garvey CJ, Sutton R, Neoptolemos JP. Fungal infection but not type of bacterial infection is associated with a high mortality in primary and secondary infected pancreatic necrosis. Digestive Surgery 2004;21 (4):297-304. [PMID: 15365228]

\section{De Vries 2007}

De Vries AC, Besselink MGH, Buskens E, Ridwan BU, Schipper M, Van Erpecum KJ, Gooszen HG. Quality, effects size and metaanalysis of randomized controlled trials of systemic antibiotic 
prophylaxis in acute necrotizing pancreatitis. Pancreatology 2007;7:531-38.

\section{De Waele 2003}

De Waele J, Vogelaers D, Blot S, Colardyn F. Fungal infections in patients with severe acute pancreatitis and the use of prophylactic therapy. Clinical Infectious Diseases 2003;37:208-13.

\section{De Waele 2004}

De Waele JJ, Vogelaers D, Hoste E, Blot S, Colardyn F. Emergence of antibiotic resistance in infected pancreatic necrosis. Archives of Surgery 2004;139(12):1371-5. [PMID: 15611464]

\section{Dervenis 1999}

Dervenis C, Johnson CD, Bassi C, Bradley E, Imrie CW, McMahon MJ, Modlin I. Diagnosis, objective assessment of severity and management of acute pancreatitis. Santorini Consensus Conference. International Journal of Pancreatology 1999;25(3):195-210.

\section{Eatock 1999}

Eatock FC, Brombacher GD, Hood J, Carter CR, Imrie CW. Fungal infection of pancreatic necrosis is associated with increased mortality. British Journal of Surgery. 1999; Vol. 86 Suppl. 1:78.

\section{Farkas 1996}

Farkas G, Márton J, Mándi Y, Szederkényi E. Surgical strategy and management of infected pancreatic necrosis. British Journal of Surgery 1996;83:930-3.

\section{Fedorak 1992}

Fedorak IJ, Ko TC, Djuricin B, McMahon M, Thompson K, Prinz RA. Secondary pancreatic infections: are they distinct clinical entities?. Surgery 1992;112:824-31.

\section{Fenton-Lee 1993}

Fento-Lee D, Imrie CW. Pancreatic necrosis: Assessment of outcome related to quality of life and cost of management. British Journal of Surgery 1993;80(12):1499-1500. [MEDLINE: 8298930]

\section{Foitzik 1997}

Foitzik T, Hotz HG, Kinzig M, Sorgel F, Buhr HJ. Influence of changes in pancreatic tissue morphology and capillary blood flow on antibiotic tissue concentrations in the pancreas during the progression of acute pancreatitis. Gut 1997;40(4):526-30.

\section{Foxx-Orenstein 1997}

Foxx-Orenstein A, Orenstein R. Antibiotics and pancreatitis. Gastroenterologist 1997;5(2):157-64.

\section{Garg 2001}

Garg PK, Khana S, Bohidar NP, Kapil A, Tandon RK. Incidence, spectrum and antibiotic sensitivity pattern of bacterial infections among patients with acute pancreatitis. Journal of Gastroenterology and Hepatology 2001;16:1055-9.

\section{Gloor 2001}

Gloor B, Müller CA, Worni M, Stahel PF, Redaelli C, Uhl W, Büchler MW. Pancreatic infection in severe pancreatitis; the role of fungus and multiresistant organisms. Archives of Surgery 2001;136:592-6.

\section{Goldacre 2004}

Goldacre MJ, Roberts SE. Hospital admission for acute pancreatitis in an English population, 1963-98: database study of incidence and mortality. BMJ 2004;328:1466-9.

\section{Golub 1998}

Golub R, Siddiqi F, Pohl D. Role of antibiotics in acute pancreatitis: A meta-analysis. Journal of Gastrointestinal Surgery 1998;2(6):496-503.

\section{Gotzinger 2001}

Gotzinger P, Wamser P, Barlan M, Sautner T, Jakesz R, Fugger R. Candida infection of local necrosis in severe acute pancreatitis is associated with increased mortality. Shock 2000;14:320-3.

\section{Grewe 1999}

Grewe M, Tsiotos GG, Luque De-Leon E, Sarr MG. Fungal infection in acute necrotizing pancreatitis. Journal of the American College of Surgeons 1999;188(4):408-14.

\section{Heinrich 2006}

Heinrich S, Schafer M, Rousson V, Clavien PA. Evidencebased treatment of acute pancreatitis. Annals of Surgery 2006;243(2):154-168.

\section{Ho 1997}

Ho hs, Frey CF. The role of antibiotic prophylaxis in severe acute pancreatitis. Archives of Surgery 1997;132:487-93.

\section{Howard 2002}

Howard TJ, Temple MB. Prophylactic antibiotics alter the bacteriology of infected necrosis in severe acute pancreatitis. Journal of the American College of Surgeons 2002;195(6):759-767. [PMID: 12495307]

\section{Isenmann 1994}

Isenmann R, Büchler MW. Infection and acute pancreatitis. British Journal of Surgery 1994;81:1707-8.

\section{Johnson 1996}

Johnson CD. Antibiotic prophylaxis in severe acute pancreatitis. British Journal of Surgery 1996;83(7):883-4.

\section{Johnson 2005}

UK Working Party on Acute Pancreatitis. UK guidelines for the management of acute pancreatitis. Gut 2005;54 (suppl III):iii1iii9. [MEDLINE: doi: 10.1136/gut.2004.057026]

\section{Kramer 1999}

Kramer KM, Levy H. Prophylactic antibiotics for severe acute pancreatitis: the beginning of an era. Pharmacotherapy 1999;19(5):592-602. 


\section{Larvin 1989}

Larvin M, Chalmers AG, Robinson PJ, McMahon MJ.

Debridement and closed cavity irrigation for the treatment of pancreatic necrosis. British Journal of Surgery 1989;76(5):465-71. [PMID 2736358]

\section{Larvin 1990}

Larvin M, Chalmers AG, McMahon MJ. Dynamic contrast enhanced computed tomography: a precise technique for identifying and localising pancreatic necrosis. British Journal of Surgery 1990;300(6):1425-8. [PMID: 2379000]

\section{Larvin 2008}

Larvin M. Management of infected pancreatic necrosis. Current Gastroenterology Reports April 2008;10(2):107-14.

\section{Luiten 1999}

Luiten EJT, Bruining HA. Antimicrobial prophylaxis in acute pancreatitis: selective decontamination versus antibiotics. Ballière's best practice and research 1999;13(2):317-30.

\section{Mazaki 2006}

Mazaki T, Ishii Y, Takayama T. Meta-analysis of prophylactic antibiotic use in acute necrotizing pancreatitis. British Journal of Surgery 2006;93:674-84.

\section{O'Reilly 2004}

O'Reilly DA, Kingsnorth AN. Management of acute pancreatitis. BMJ 2004;328:968-9.

\section{Powell 1998}

Powell JJ, Miles R, Siriwardena AK. Antibiotic prophylaxis in the initial management of severe acute pancreatitis. British Journal of Surgery 1998;85:582-7.

\section{Powell 1999}

Powell JJ, Campbell E, Johnson CD, Siriwardena AK. Survey of antibiotic prophylaxis in the treatment of acute pancreatitis. British Journal of Surgery 1999;86(3):320-2.

\section{Rahman 2003}

Rahman SH, Ammori BJ, Holmfield J, Larvin M, McMahon MJ. Intestinal hypoperfusion contributes to gut barrier failure in severe acute pancreatitis. Journal of Gastrointestinal Surgery 2003;7(1):26-35. [PMID: 12559182]

\section{Ratschko 1999}

Ratschko M, Fenner T, Lankisch PG. The role of antibiotic prophylaxis in the treatment of acute pancreatitis. Gastroenterology Clinics of North America 1999;28(3):641-59.

\section{Rünzi 1999}

Rünzi M, Layer P. Nonsurgical management of acute pancreatitis. Use of antibiotics. Surgical Clinics of North America 1999;79(4):759-65.

\section{CHARACTERISTICS OF STUDIES}

Characteristics of included studies [ordered by study ID]

\section{Sandzén 2009}

Sandzén B, Rosenmüller M, Haapamäki MM, Nilsson E, Stenlund HC, Öman M. First attack of acute pancreatitis in Sweden 1988 - 2003: incidence, aetiological classification, procedures and mortality - a register study. $B M C$ Gastroenterology 5 March 2009;9:80.

\section{Sharma 2001}

Sharma VK, Howden CW. Prophylactic antibiotic administration reduces sepsis and mortality in acute necrotizing pancreatitis: a meta-analysis. Pancreas 2001;22(1):28-31.

\section{Steinberg 1994}

Steinberg W, Tenner S. Acute pancreatitis. New England Journal of Medicine 1994;330(17):1198-210.

\section{Tinto 2002}

Tinto A, Lloyd DAJ, Kang JY, Majeed A, Ellis C, Williamson RCN, Maxwell JD. Acute and chronic pancreatitis -diseases on the rise: a study of hospital admissions in England 1989/90 1999/2000. Aliment Pharmacol Ther 2002;16:2097-105.

\section{Werner 2003}

Werner J, Uhl W, Hartwig W, Hackert T, Müller C, Strobel O, Büchler MW. Modern phase-specific management of acute pancreatitis. Digestive Diseases 2003;21(1):38-45. [MEDLINE: 12837999]

\section{Werner 2005}

Werner J, Feuerbach S, Uhl W, Büchler MW. Management of acute pancreatitis: from surgery to intensive care. Gut 2005;54(3):426-36. [MEDLINE: 15710995]

\section{Werner 2007}

Werner J, Hartwig W, Büchler MW. Antibiotic prophylaxis: An ongoing controversy in the treatment of severe acute pancreatitis. Scandinavian Journal of Gastroenterology 2007;42:667-72.

\section{References to other published versions of this review Villatoro 2003}

Villatoro E, Larvin M, Bassi C. Antibiotic therapy for prophylaxis against infection of pancreatic necrosis in acute pancreatitis. Cochrane Database of Systematic Reviews 2003, Issue 4. [DOI: 10.1002/14651858.CD002941.pub1; MEDLINE: 14583957]

\section{Villatoro 2006}

Villatoro E, Bassi C, Larvin M. Antibiotic therapy for prophylaxis against infection of pancreatic necrosis in acute pancreatitis. Cochrane Database of Systematic Reviews 2006, Issue 4. [DOI: 10.1002/14651858.CD002941.pub2; MEDLINE: 17054156]

* Indicates the major publication for the study 
Dellinger 2007

\begin{tabular}{|c|c|c|}
\hline Methods & \multicolumn{2}{|c|}{$\begin{array}{l}\text { Randomised, placebo-controlled, double-blind trial. } \\
\text { Method of randomisation: random computerised allocation. } \\
\text { Complete follow-up: yes. } \\
\text { Comparable groups: yes. }\end{array}$} \\
\hline Participants & \multicolumn{2}{|c|}{$\begin{array}{l}100 \text { patients with severe AP and proven pancreatic necrosis on CT, or Balthazar grade E with either CR- } \\
\text { P>120mg/L or MOD score of }>2 \text {. } \\
\text { Setting: Multicenter (US and Europe) } \\
\text { February } 2003 \text { - December } 2004\end{array}$} \\
\hline Interventions & \multicolumn{2}{|c|}{$\begin{array}{l}50 \text { patients received supportive treatment, and meropenem (1g every } 8 \text { hours) for a minimum of } 7 \text { days } \\
\text { and a maximum of } 21 \text { days (recommended duration } 14 \text { days). The other } 50 \text { received supportive treat- } \\
\text { ment and placebo. } 31 \text { patients in the treatment group, and } 32 \text { in the placebo group, received the study } \\
\text { drug for less than } 14 \text { days. } 11 \text { patients in the meropenem group, and } 10 \text { in the placebo group, had the } \\
\text { drug stopped because of diagnosis of infection and starting of non-study antibiotics or surgery. }\end{array}$} \\
\hline Outcomes & \multicolumn{2}{|c|}{$\begin{array}{l}\text { Main end-point: Reduction of pancreatic/peripancreatic infection. } \\
\text { Requirement for operative debridement } \\
\text { Mortality }\end{array}$} \\
\hline Notes & \multicolumn{2}{|c|}{ Double-blind placebo-controlled } \\
\hline \multicolumn{3}{|l|}{ Risk of bias } \\
\hline Bias & Authors' judgement & Support for judgement \\
\hline $\begin{array}{l}\text { Adequate sequence gener- } \\
\text { ation? }\end{array}$ & Low risk & $\begin{array}{l}\text { Sequential sealed envelopes with numbers randomly generated by a comput- } \\
\text { er software opened by pharmacist preparing the placebo or meropenem solu- } \\
\text { tion when patient enrolled into the study. }\end{array}$ \\
\hline Allocation concealment? & Low risk & Adequate \\
\hline $\begin{array}{l}\text { Blinding? } \\
\text { All outcomes }\end{array}$ & Low risk & $\begin{array}{l}\text { Opaque zip-lock covers placed over infusion bags, and transparent yellow ad- } \\
\text { hesive tape affixed to the drip regulators. }\end{array}$ \\
\hline
\end{tabular}

Isenmann 2004

\begin{tabular}{ll}
\hline Methods & Randomised, placebo-controlled, double-blind trial. \\
& Method of randomisation: consecutive numbers. \\
Complete follow-up: yes. \\
Comparable groups: yes
\end{tabular}


Isenmann 2004 (Continued)

Outcomes Main end-point: Reduction of the incidence of infected pancreatic necrosis.

Mortality

Extrapancreatic infection

Pancreatic necrosectomy

Intensive Care Unit stay

Hospital stay

Systemic complications

\begin{tabular}{ll}
\hline Notes & $\begin{array}{l}\text { Double-blind } \\
\text { placebo-controlled }\end{array}$ \\
\hline
\end{tabular}

\section{Risk of bias}

\begin{tabular}{lll}
\hline Bias & Authors' judgement & Support for judgement \\
\hline $\begin{array}{l}\text { Adequate sequence gener- } \\
\text { ation? }\end{array}$ & Unclear risk & $\begin{array}{l}\text { Stratified randomisation plan generated prior to commencement of study, us- } \\
\text { ing a block size of 4 patients. Sequential allocation. }\end{array}$ \\
\hline Allocation concealment? & Low risk & Adequate \\
\hline $\begin{array}{l}\text { Blinding? } \\
\text { All outcomes }\end{array}$ & Low risk & $\begin{array}{l}\text { Study medication packed in identical vials and labelled with consecutive pa- } \\
\text { tient numbers according to the randomisation sequence. }\end{array}$ \\
\hline
\end{tabular}

Nordback 2001

\begin{tabular}{|c|c|}
\hline Methods & $\begin{array}{l}\text { Randomised Controlled Trial. } \\
\text { Method of randomisation: Not stated. } \\
\text { Complete follow-up: yes. } \\
\text { Comparable groups: yes. }\end{array}$ \\
\hline Participants & $\begin{array}{l}58 \text { patients with severe acute pancreatitis and pancreatic necrosis. } \\
\text { Severity based on CRP concentration }>150 \mathrm{mg} / \mathrm{L} \text { and CT. } \\
\text { Setting: Tampere, Finland. } \\
\text { September } 1995 \text { - May } 1999 .\end{array}$ \\
\hline
\end{tabular}

Interventions

33 patients (age $46+/-7$ ) received supportive treatment without prophylactic antibiotics. Of these, Imipenem was started when clinically indicated (consistent increase in inflammatory markers or positive CT/USS guided FNA of pancreatic necrosis) in 14 patients, of whom 5 needed necrosectomy at least 3 days later.

25 patients (age $47+/-8$ ) received supportive treatment and prophylactic antibiotics (imipenem $1 \mathrm{~g}$ iv tds). The duration of the prophylactic antibiotic regimen was not stated in the study.

\begin{tabular}{ll}
\hline Outcomes & $\begin{array}{l}\text { Main end-point: Indication for necrosectomy due to infection. } \\
\text { Mortality. } \\
\text { Morbidity. } \\
\text { Intensive Care Unit stay. } \\
\text { Hospital stay. }\end{array}$ \\
\hline Notes & Single-blind \\
\hline Risk of bias & Authors' judgement Support for judgement \\
\hline Bias &
\end{tabular}


Nordback 2001 (Continued)

\begin{tabular}{|c|c|c|}
\hline $\begin{array}{l}\text { Adequate sequence gener- } \\
\text { ation? }\end{array}$ & Unclear risk & Not stated \\
\hline Allocation concealment? & High risk & Not stated \\
\hline $\begin{array}{l}\text { Blinding? } \\
\text { All outcomes }\end{array}$ & High risk & No \\
\hline
\end{tabular}

\section{Pederzoli 1993}

\begin{tabular}{|c|c|c|}
\hline Methods & \multicolumn{2}{|c|}{$\begin{array}{l}\text { Randomized Controlled Trial. } \\
\text { Method of Randomization: Casual numbers table. } \\
\text { Complete follow-up: yes. } \\
\text { Comparable groups: yes. }\end{array}$} \\
\hline Participants & \multicolumn{2}{|c|}{$\begin{array}{l}74 \text { patients with severe acute pancreatitis and pancreatic necrosis proven on CT. } \\
\text { Setting: } 6 \text { Italian centres. } \\
\text { January } 1989 \text { - July } 1991 .\end{array}$} \\
\hline Interventions & \multicolumn{2}{|c|}{$\begin{array}{l}33 \text { patients (mean age } 50 \text { ) received intensive medical treatment with no prophylactic antibiotics. } \\
41 \text { patients (mean age } 54 \text { ) received intensive medical treatment with prophylactic antibiotics (imipen- } \\
\text { em } 500 \mathrm{mg} \text { iv tds) for } 14 \text { days from } \mathrm{CT} \text { demonstration of pancreatic necrosis. }\end{array}$} \\
\hline Outcomes & \multicolumn{2}{|c|}{$\begin{array}{l}\text { Incidence of pancreatic sepsis. } \\
\text { Co-morbidity. } \\
\text { Mortality. } \\
\text { Pancreatic necrosectomy. }\end{array}$} \\
\hline Notes & \multicolumn{2}{|l|}{ Single-blind } \\
\hline \multicolumn{3}{|l|}{ Risk of bias } \\
\hline Bias & Authors' judgement & Support for judgement \\
\hline $\begin{array}{l}\text { Adequate sequence gener- } \\
\text { ation? }\end{array}$ & Unclear risk & Casual numbers table \\
\hline Allocation concealment? & Low risk & Patients were allocated after informed consent had been given \\
\hline $\begin{array}{l}\text { Blinding? } \\
\text { All outcomes }\end{array}$ & High risk & No \\
\hline
\end{tabular}

Røkke 2007

\begin{tabular}{ll}
\hline Methods & Randomised Controlled Trial. \\
& Method of Randomization: Not stated \\
& Complete follow-up: yes. \\
& Comparable groups: yes.
\end{tabular}

Participants

73 patients with severe acute pancreatitis (necrosis demonstrated on CT and/or elevated serum CRP) Setting: 7 Hospitals in Norway. 1997 - 2002. 
Røkke 2007 (Continued)

Interventions

Outcomes
36 patients received early antibiotic treatment with imipenem ( $500 \mathrm{mg}$ iv tds), and 37 patients received antibiotics only when clinically indicated.

Reduction of septic complications, and delay on the onset of infection was postponed to the 3rd week in the treatment group.

Notes Unblinded

\section{Risk of bias}

\begin{tabular}{lll}
\hline Bias & Authors' judgement & Support for judgement \\
\hline $\begin{array}{l}\text { Adequate sequence gener- } \\
\text { ation? }\end{array}$ & Unclear risk & Not stated. \\
\hline Allocation concealment? & Low risk & Patients were allocated after informed consent had been given \\
\hline $\begin{array}{l}\text { Blinding? } \\
\text { All outcomes }\end{array}$ & High risk & No \\
\hline
\end{tabular}

Sainio 1995

$\begin{array}{ll}\text { Methods } & \text { Randomized Controlled Trial. } \\ & \text { Method of Randomization: Numbered envelopes. } \\ \text { Complete follow-up: yes. } \\ \text { Comparable groups: yes. }\end{array}$

Interventions $\quad 30$ patients (age $38.7+/-8.4$ ) received supportive medical treatment with antibiotics started only when clinically, microbiologically or radiologically indicated or when there was a secondary raise in the CRP > $20 \%$ after the acute phase.

30 patients (age $43.0+/$ - 11.3) received supportive medical treatment and prophylactic antibiotics (cefuroxime $1.5 \mathrm{~g}$ iv tds) from admission and until clinical recovery and fall to normal CRP concentration; in cases of clinical recovery but moderately raised CRP concentration oral antibiotics (cefuroxime $250 \mathrm{mg}$ p.o. bd) were continued for 14 days.

\begin{tabular}{ll}
\hline Outcomes & $\begin{array}{l}\text { Incidence of pancreatic sepsis. } \\
\text { Other infections. } \\
\text { Necrosectomy. } \\
\text { Intensive Care Unit stay. } \\
\text { Hospital stay. } \\
\text { Mortality. }\end{array}$ \\
\hline Notes & Single-blind \\
\hline Risk of bias & Authors' judgement Support for judgement \\
\hline Bias &
\end{tabular}


Sainio 1995 (Continued)

\begin{tabular}{|c|c|c|}
\hline $\begin{array}{l}\text { Adequate sequence gener- } \\
\text { ation? }\end{array}$ & Unclear risk & Sequential sealed envelopes \\
\hline Allocation concealment? & Unclear risk & Not stated \\
\hline $\begin{array}{l}\text { Blinding? } \\
\text { All outcomes }\end{array}$ & High risk & No \\
\hline
\end{tabular}

\section{Schwarz 1997}

\begin{tabular}{ll}
\hline Methods & Randomized Controlled Trial. \\
& Method of Randomization: Not stated. \\
& Complete follow-up: yes. \\
& Comparable groups: yes. \\
\hline Participants & $\begin{array}{l}\text { 26 patients with severe acute pancreatitis (?Atlanta criteria). } \\
\text { Setting: Ulm University Hospital, Germany. } \\
\text { August } 1991 \text { - October 1994. }\end{array}$
\end{tabular}

Interventions

13 patients with severe AP and sterile necrosis (mean age 46 [24-71]) received supportive medical treatment with antibiotics started only when clinically indicated or evidence of infection of the necrotic pancreatic tissue was obtained.

13 patients with severe AP and sterile necrosis (mean age 43 [31 - 82]) received supportive medical treatment and prophylactic antibiotics (ofloxacin $200 \mathrm{mg}$ b.d. i.v. and metronidazole $500 \mathrm{mg}$ b.d. i.v.) for 10 days.

\begin{tabular}{lll}
\hline Outcomes & $\begin{array}{l}\text { Mortality. } \\
\text { Incidence of pancreatic sepsis. } \\
\text { Co-morbidity. }\end{array}$ \\
\hline Notes & Single-blind & \\
\hline Risk of bias & Authors' judgement & Support for judgement \\
\hline Bias & Unclear risk & Not stated \\
\hline $\begin{array}{l}\text { Adequate sequence gener- } \\
\text { ation? }\end{array}$ & Unclear risk & Not stated \\
\hline Allocation concealment? & High risk & No \\
\hline $\begin{array}{l}\text { Blinding? } \\
\text { All outcomes }\end{array}$ & \\
\hline
\end{tabular}

\section{Glossary of abbreviated terms}

AP : Acute Pancreatitis ; b.d.: Bis die (Latin for 'twice a day'); CRP: C Reactive Protein; CT: Computerised Tomography; FNA: Fine Needle Aspiration; i.v.: intravenously; MOD: Multiple Organ Dysfunction; p.o.: Per os (Latin for 'by mouth'); t.d.s.: Ter die sumendus (Latin for "three times a day"); USS: Ultrasound scan.

\section{Characteristics of excluded studies [ordered by study ID]}




\begin{tabular}{|c|c|}
\hline Study & Reason for exclusion \\
\hline Bassi 1998 & Assesses the use of pefloxacin versus imipenem in severe acute pancreatitis, with no control group. \\
\hline Craig 1975 & $\begin{array}{l}\text { This is an RCT looking into the efficacy of ampicillin in the treatment of acute pancreatitis. Pub- } \\
\text { lished in } 1975 \text { dates from the pre-CT era, and included participants with varying degrees of severity } \\
\text { of acute pancreatitis. }\end{array}$ \\
\hline Delcenserie 1996 & $\begin{array}{l}\text { This is an RCT looking into the role of prophylactic antibiotics in severe acute pancreatitis with one } \\
\text { or more collections demonstrated on CT but with no mention of pancreatic necrosis, therefore not } \\
\text { meeting the inclusion criteria set out in our protocol. }\end{array}$ \\
\hline Finch 1976 & $\begin{array}{l}\text { RCT published in 1976, pre-CT era, looking into the use of ampicillin in acute pancreatitis with vary- } \\
\text { ing degrees of severity. }\end{array}$ \\
\hline Gelfand 2001 & Only one arm in the study assessing pefloxacin in pancreatonecrosis. No control group. \\
\hline Howes 1975 & $\begin{array}{l}\text { Another RCT published in 1975, pre-CT era, looking into the use of ampicillin in acute pancreatitis } \\
\text { with varying degrees of severity. }\end{array}$ \\
\hline Imaizumi 2004 & $\begin{array}{l}\text { Does not assess antibiotic prophylaxis alone, but together with protease inhibitors. These are de- } \\
\text { livered via continuous regional arterial infusion. }\end{array}$ \\
\hline Luiten 1995 & $\begin{array}{l}\text { This is a multicenter RCT evaluating the role of prophylactic antibiotics with selective gut deconta- } \\
\text { mination in severe acute pancreatitis. Criteria for admission was a CT Balthazar grade D or E, which } \\
\text { does not comment on pancreatic necrosis. }\end{array}$ \\
\hline Manes 2006 & $\begin{array}{l}\text { Compares two groups receiving antibiotics (meropenem) started early or late in the disease, with } \\
\text { no control (no antibiotic) group. }\end{array}$ \\
\hline Maravi-Poma 2003 & $\begin{array}{l}\text { Assesses two different concentrations of imipenem with cilastatin as prophylaxis in necrotising } \\
\text { pancreatitis, with no control group. }\end{array}$ \\
\hline Takeda 1996 & $\begin{array}{l}\text { Does not assess antibiotic prophylaxis alone, but together with protease inhibitors. These are de- } \\
\text { livered via continuous regional arterial infusion. }\end{array}$ \\
\hline
\end{tabular}

Characteristics of studies awaiting assessment [ordered by study ID]

\section{Barreda 2009}

Methods

\section{Participants}

Interventions

\section{Outcomes}

Notes 
García-Barrasa 2009 (Continued)

Participants

\author{
Interventions
}

Outcomes

\title{
Notes
}

\section{Spicak 2002}

\begin{tabular}{ll} 
Methods & $\begin{array}{l}\text { Randomized Controlled Trial. } \\
\text { Method of Randomization: Not stated. } \\
\text { Complete follow-up: yes. } \\
\text { Comparable groups: yes. }\end{array}$ \\
\hline Participants & $\begin{array}{l}63 \text { participants with severe acute pancreatitis (Atlanta criteria or CRP>150mg/l). } \\
\text { Setting: Multicentre - Czech Republic. } \\
1999 \text { - } 2001 .\end{array}$ \\
\hline Interventions & $\begin{array}{l}30 \text { participants with severe acute pancreatitis received supportive medical treatment with antibi- } \\
\text { otics started only when clinically indicated. }\end{array}$ \\
& $\begin{array}{l}33 \text { participants with severe acute pancreatitis received supportive medical treatment and prophy- } \\
\text { lactic antibiotics (ciprofloxacin 200mg b.d. i.v. and metronidazole 500mg b.d. i.v.). }\end{array}$ \\
\hline Outcomes & $\begin{array}{l}\text { Mortality. } \\
\text { Incidence of pancreatic sepsis. } \\
\text { Hospital stay }\end{array}$ \\
\hline Unable to extract number of participants with necrotising pancreatitis after enquiries to authors, \\
therefore unable to include study in this review.
\end{tabular}

Spicak 2003

$\begin{array}{ll}\text { Methods } & \text { Randomized Controlled Trial. } \\ & \text { Method of Randomization: Not stated. } \\ & \text { Complete follow-up: Not stated. } \\ & \text { Comparable groups: Not stated. }\end{array}$

\section{Participants}

41 participants with severe acute pancreatitis (Atlanta criteria or CRP>190mg/l). Setting: Multicentre - Czech Republic.

Time period not stated.

Interventions

20 participants with severe acute pancreatitis received supportive medical treatment with antibiotics started only when clinically indicated.

21 participants with severe acute pancreatitis received supportive medical treatment and prophylactic antibiotics (meropenem 500mg t.d.s. i.v.).

$\begin{array}{ll}\text { Outcomes } & \text { Mortality. } \\ \text { Surgical treatment. }\end{array}$


Spicak 2003 (Continued)

Infectious complications.

Local complications.

Mean hospital stay.

Notes

Unable to extract number of participants with necrotising pancreatitis after enquiries to authors, therefore unable to include study in this review.

\section{Spicak 2004}

\begin{tabular}{|c|c|}
\hline Methods & $\begin{array}{l}\text { Randomized Controlled Trial. } \\
\text { Method of Randomization: Not stated. } \\
\text { Complete follow-up: Not stated. } \\
\text { Comparable groups: Not stated. }\end{array}$ \\
\hline Participants & $\begin{array}{l}35 \text { participants with acute necrotising pancreatitis (CT or autopsy). } \\
\text { Setting: Multicentre - Czech Republic. } \\
\text { Time period not stated. }\end{array}$ \\
\hline Interventions & $\begin{array}{l}17 \text { participants with acute necrotising pancreatitis received supportive medical treatment with an- } \\
\text { tibiotics started only when clinically indicated. } \\
18 \text { participants with acute necrotising pancreatitis received supportive medical treatment and } \\
\text { prophylactic antibiotics (either ciprofloxacin } 200 \mathrm{mg} \text { b.d. iv and metronidazole } 500 \mathrm{mg} \text { i.v. t.d.s. or } \\
\text { meropenem } 500 \mathrm{mg} \text { t.d.s. i.v.). }\end{array}$ \\
\hline Outcomes & $\begin{array}{l}\text { Mortality. } \\
\text { Surgical treatment. } \\
\text { Infected necrosis. } \\
\text { Other infectious complications. } \\
\text { Mean hospital stay. }\end{array}$ \\
\hline Notes & $\begin{array}{l}\text { This report appears to incorporate data from participants in both studies previously published by } \\
\text { the authors. Enquiries for further information have been unsuccessful, therefore this study was not } \\
\text { included in the present review. }\end{array}$ \\
\hline
\end{tabular}

Xue 2009

Methods

Participants

Interventions

Outcomes

\section{Notes}




\section{DATA AND ANALYSES}

Comparison 1. Antibiotics versus control

\begin{tabular}{llllll}
\hline Outcome or subgroup title & $\begin{array}{l}\text { No. of } \\
\text { studies }\end{array}$ & $\begin{array}{l}\text { No. of } \\
\text { partici- } \\
\text { pants }\end{array}$ & Statistical method & Effect size \\
\hline 1 Mortality & 7 & 404 & Risk Ratio (M-H, Fixed, 95\% Cl) & $0.60[0.34,1.05]$ \\
\hline 2 Infected Pancreatic Necrosis & 7 & 404 & Risk Ratio (M-H, Random, 95\% Cl) & $0.85[0.57,1.26]$ \\
\hline 3 Non-Pancreatic Infections & 5 & 318 & Risk Ratio (M-H, Random, 95\% Cl) & $0.62[0.36,1.06]$ \\
\hline 4 All sites infections & 5 & 318 & Risk Ratio (M-H, Random, 95\% Cl) & $0.69[0.44,1.09]$ \\
\hline 5 Fungal Infection & 7 & 404 & Risk Ratio (M-H, Random, 95\% Cl) & $1.06[0.41,2.70]$ \\
\hline 6 Operative Treatment & 6 & 378 & Risk Ratio (M-H, Random, 95\% Cl) & $0.90[0.62,1.31]$ \\
\hline
\end{tabular}

Analysis 1.1. Comparison 1 Antibiotics versus control, Outcome 1 Mortality.

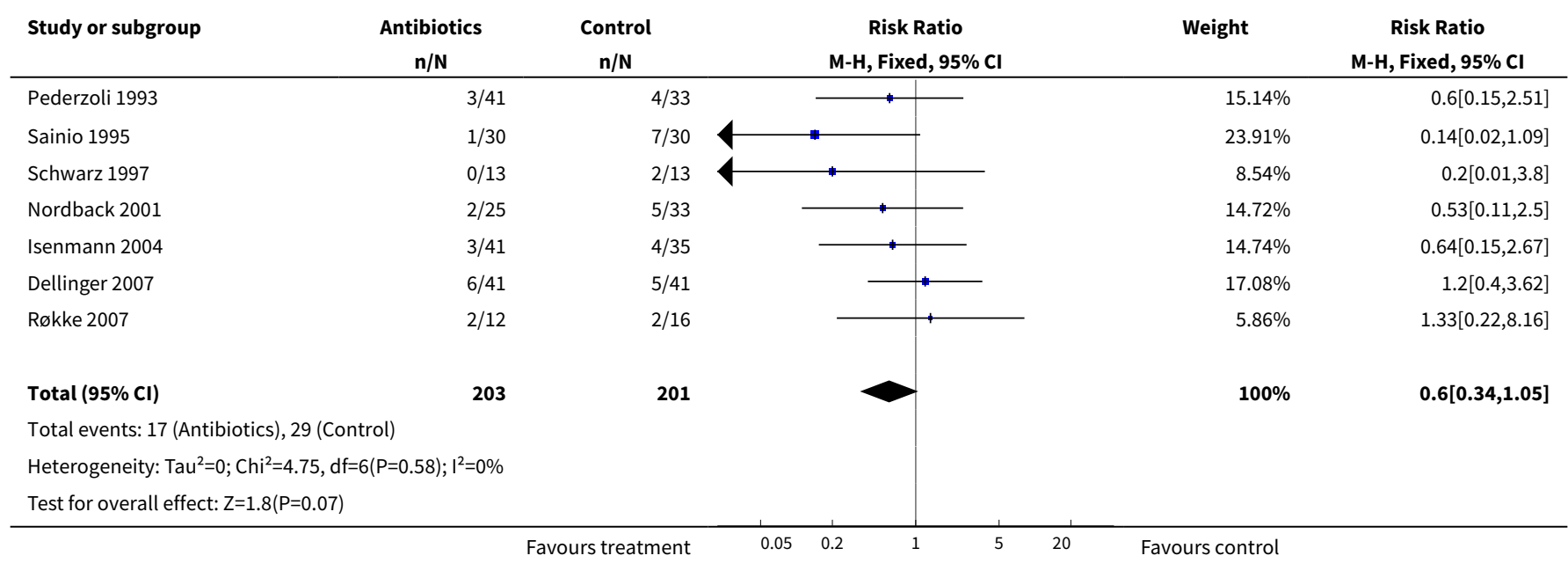

Analysis 1.2. Comparison 1 Antibiotics versus control, Outcome 2 Infected Pancreatic Necrosis.

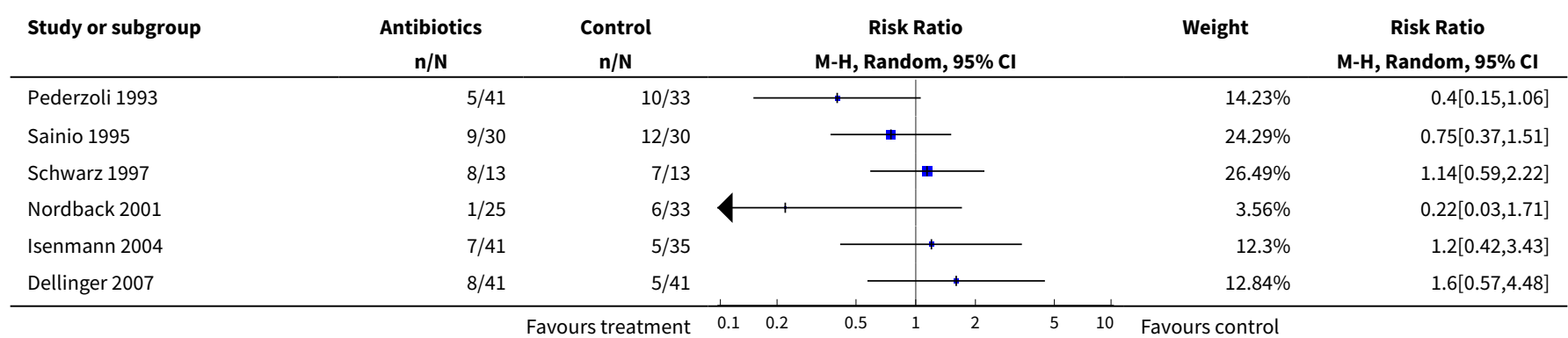




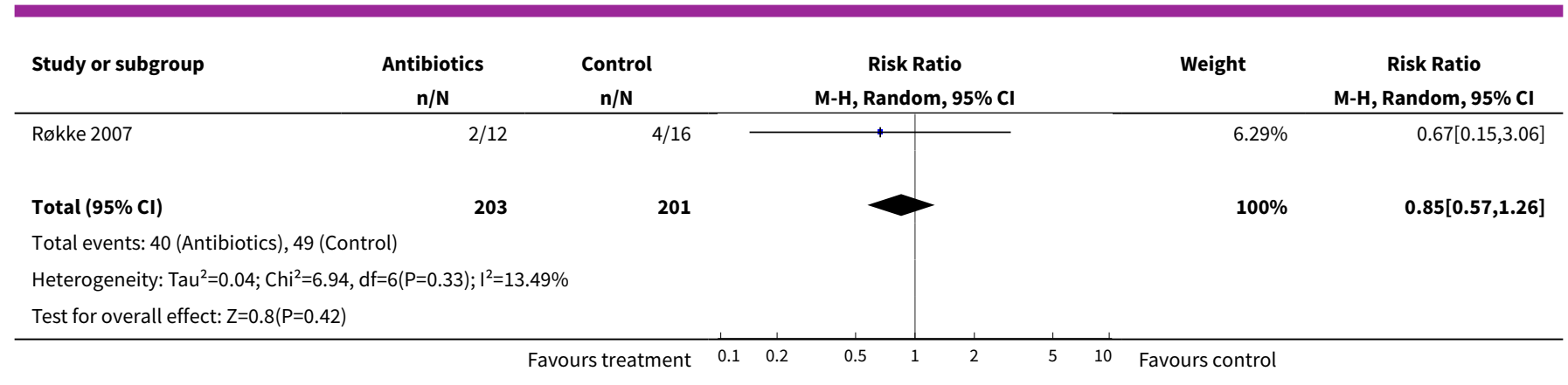

Analysis 1.3. Comparison 1 Antibiotics versus control, Outcome 3 Non-Pancreatic Infections.

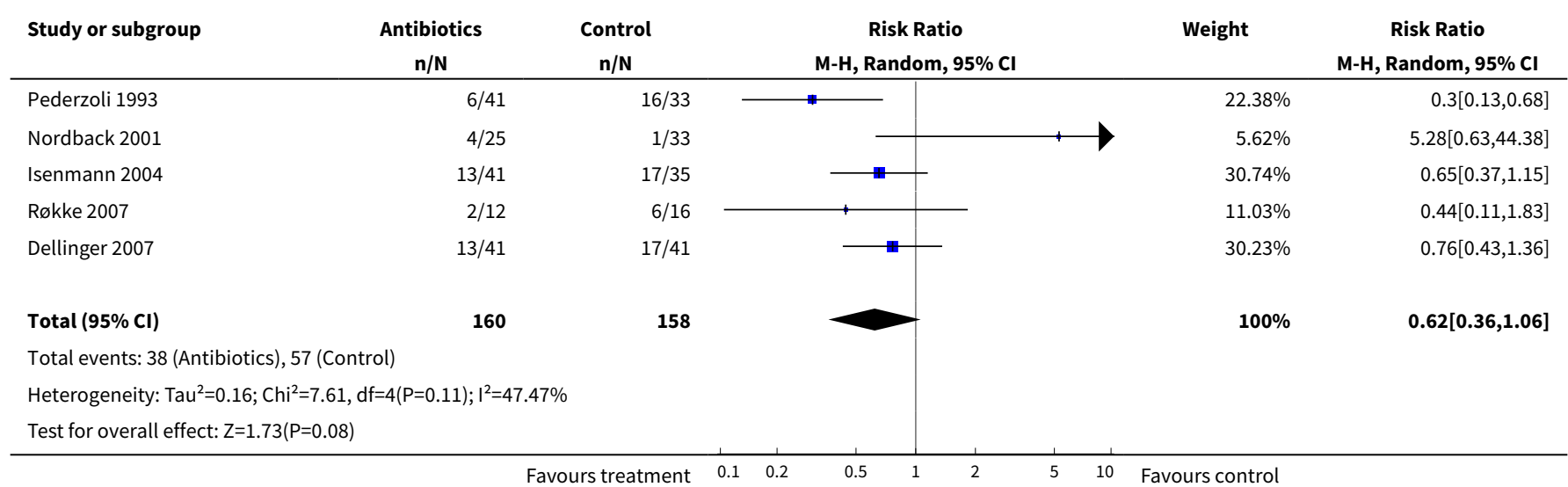

Analysis 1.4. Comparison 1 Antibiotics versus control, Outcome 4 All sites infections.

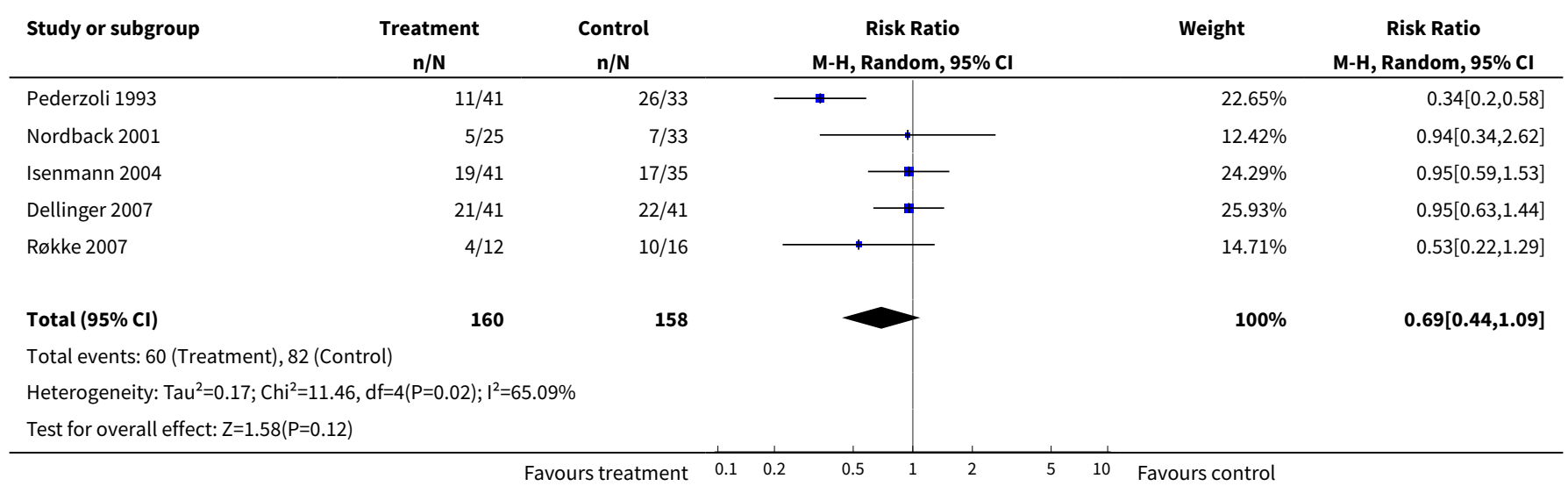


Analysis 1.5. Comparison 1 Antibiotics versus control, Outcome 5 Fungal Infection.

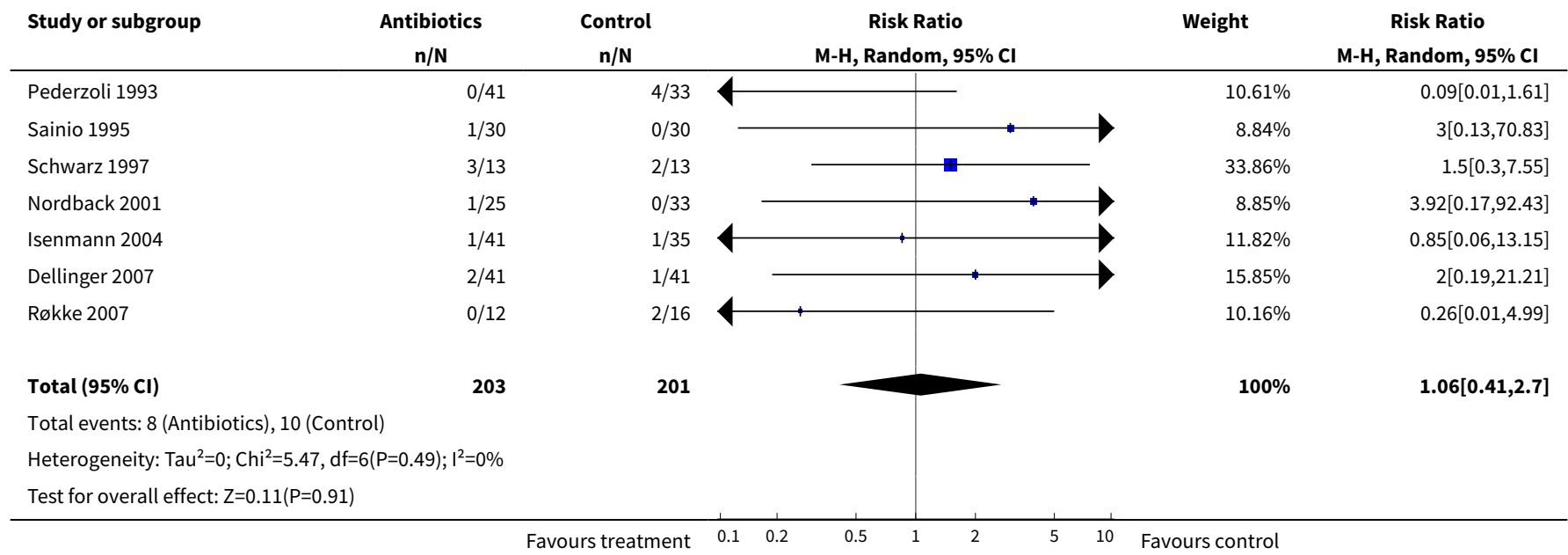

Analysis 1.6. Comparison 1 Antibiotics versus control, Outcome 6 Operative Treatment.

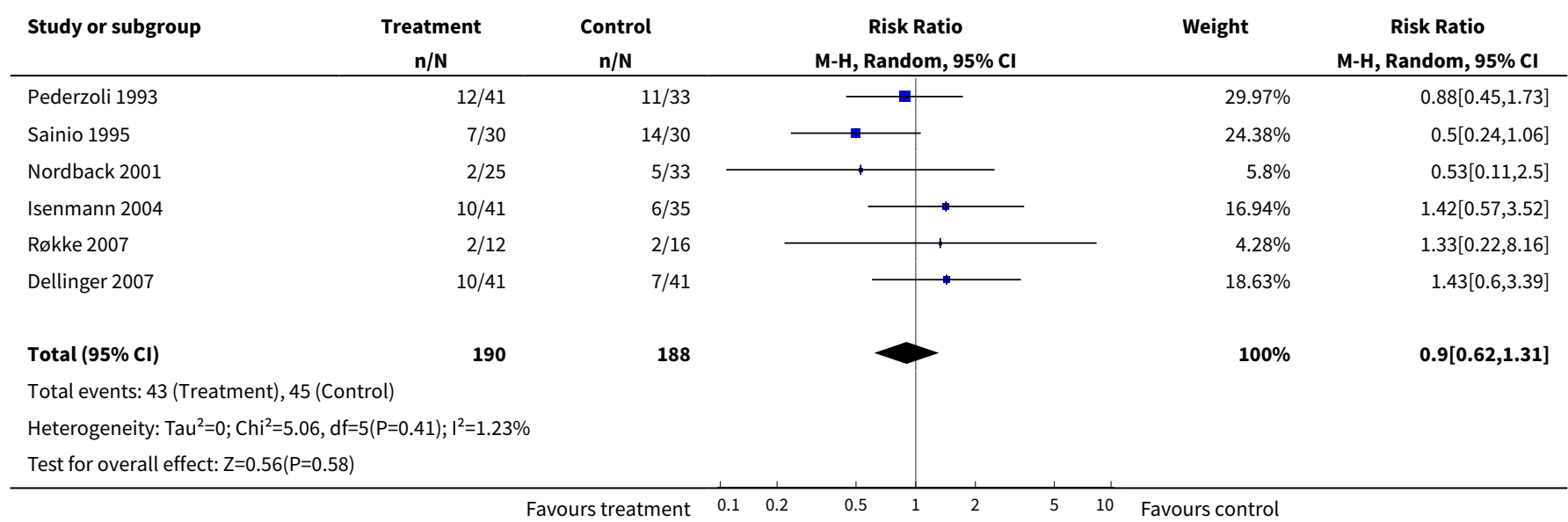

\section{Comparison 2. Beta-lactam versus control}

\begin{tabular}{lllll}
\hline Outcome or subgroup title & $\begin{array}{l}\text { No. of } \\
\text { studies }\end{array}$ & $\begin{array}{l}\text { No. of } \\
\text { partici- } \\
\text { pants }\end{array}$ & Statistical method & Effect size \\
\hline 1 Mortality (beta-lactam) & 5 & 302 & Risk Ratio (M-H, Random, 95\% Cl) & $0.72[0.37,1.40]$ \\
\hline $\begin{array}{l}2 \text { Infected Pancreatic Necrosis (be- } \\
\text { ta-lactam) }\end{array}$ & 5 & 302 & Risk Ratio (M-H, Random, 95\% Cl) & $0.69[0.40,1.19]$ \\
\hline $\begin{array}{l}3 \text { Non-Pancreatic Infections (be- } \\
\text { ta-lactam) }\end{array}$ & 4 & 242 & Risk Ratio (M-H, Random, 95\% Cl) & $0.64[0.28,1.47]$ \\
\hline 4 All sites infections (beta-lactam) & 4 & 242 & Risk Ratio (M-H, Random, 95\% Cl) & $0.63[0.35,1.13]$
\end{tabular}




\begin{tabular}{lllll}
\hline Outcome or subgroup title & $\begin{array}{l}\text { No. of } \\
\text { studies }\end{array}$ & $\begin{array}{l}\text { No. of } \\
\text { partici- } \\
\text { pants }\end{array}$ & Statistical method & Effect size \\
\hline 5 Fungal Infection (beta-lactam) & 5 & 302 & Risk Ratio (M-H, Random, 95\% Cl) & $0.88[0.21,3.76]$ \\
\hline $\begin{array}{l}\text { 6 Operative Treatment (beta-lac- } \\
\text { tam) }\end{array}$ & 5 & 302 & Risk Ratio (M-H, Random, 95\% Cl) & $0.82[0.54,1.23]$ \\
\hline
\end{tabular}

\section{Analysis 2.1. Comparison 2 Beta-lactam versus control, Outcome 1 Mortality (beta-lactam).}

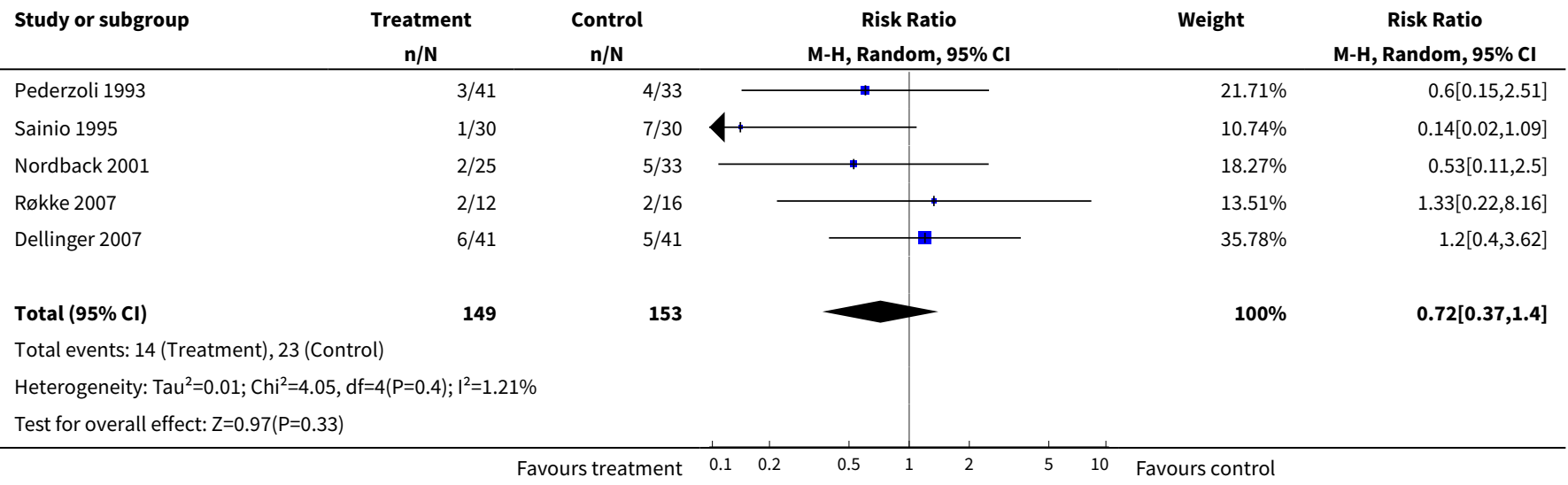

\section{Analysis 2.2. Comparison 2 Beta-lactam versus control, Outcome 2 Infected Pancreatic Necrosis (beta-lactam).}

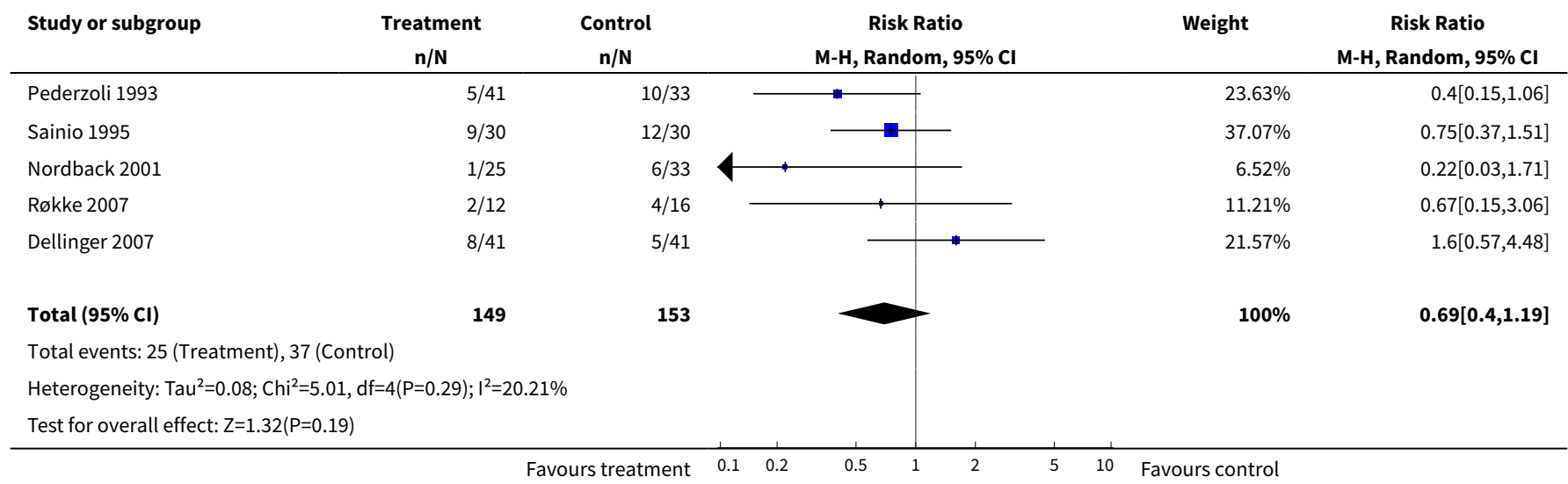

Analysis 2.3. Comparison 2 Beta-lactam versus control, Outcome 3 Non-Pancreatic Infections (beta-lactam).

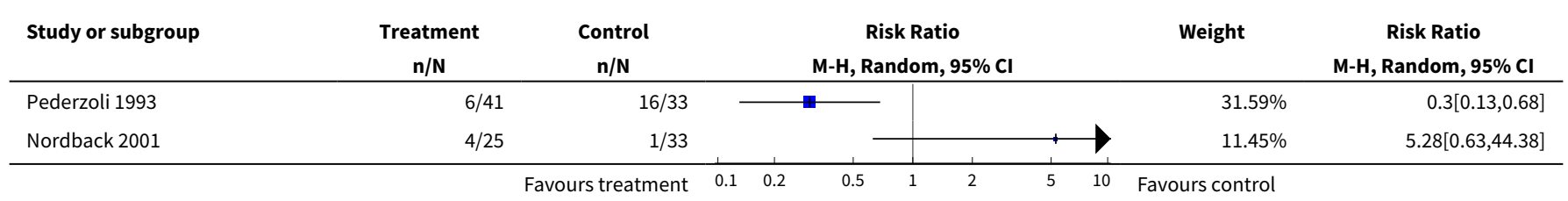




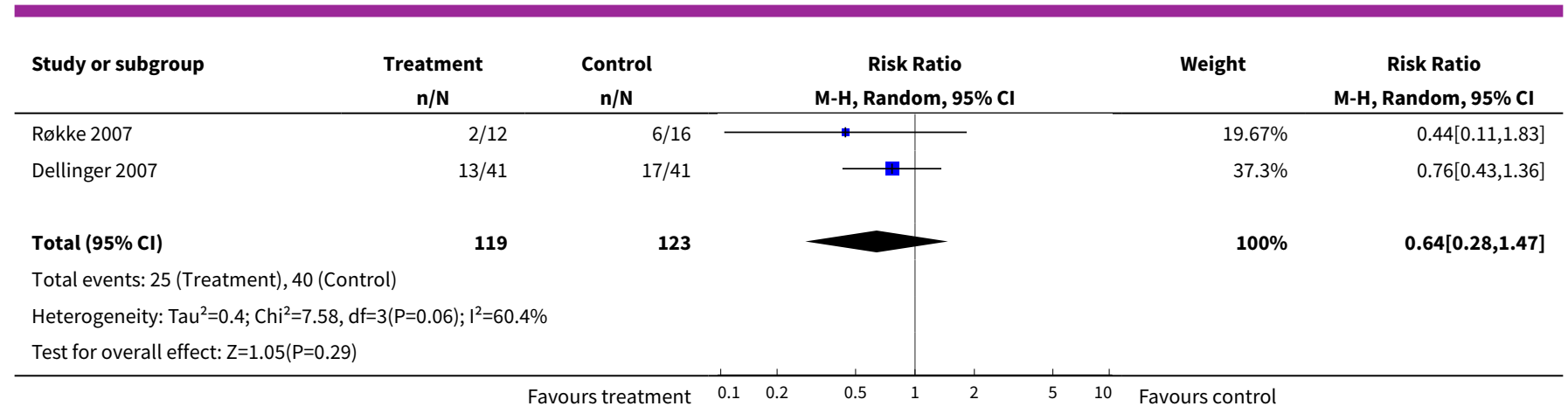

Analysis 2.4. Comparison 2 Beta-lactam versus control, Outcome 4 All sites infections (beta-lactam).

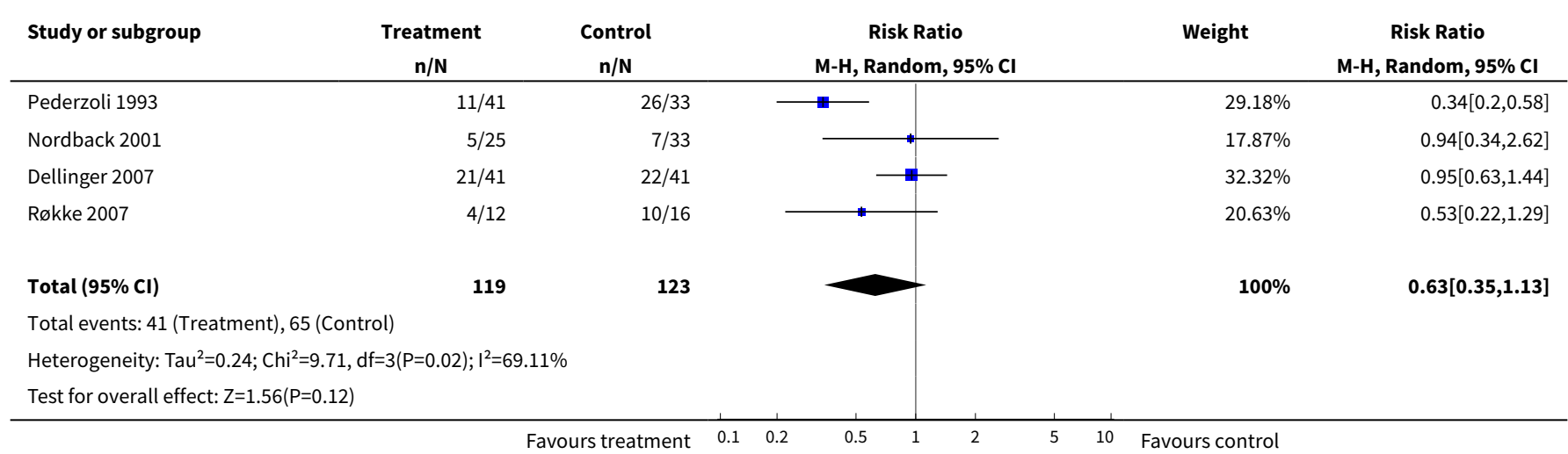

Analysis 2.5. Comparison 2 Beta-lactam versus control, Outcome 5 Fungal Infection (beta-lactam).

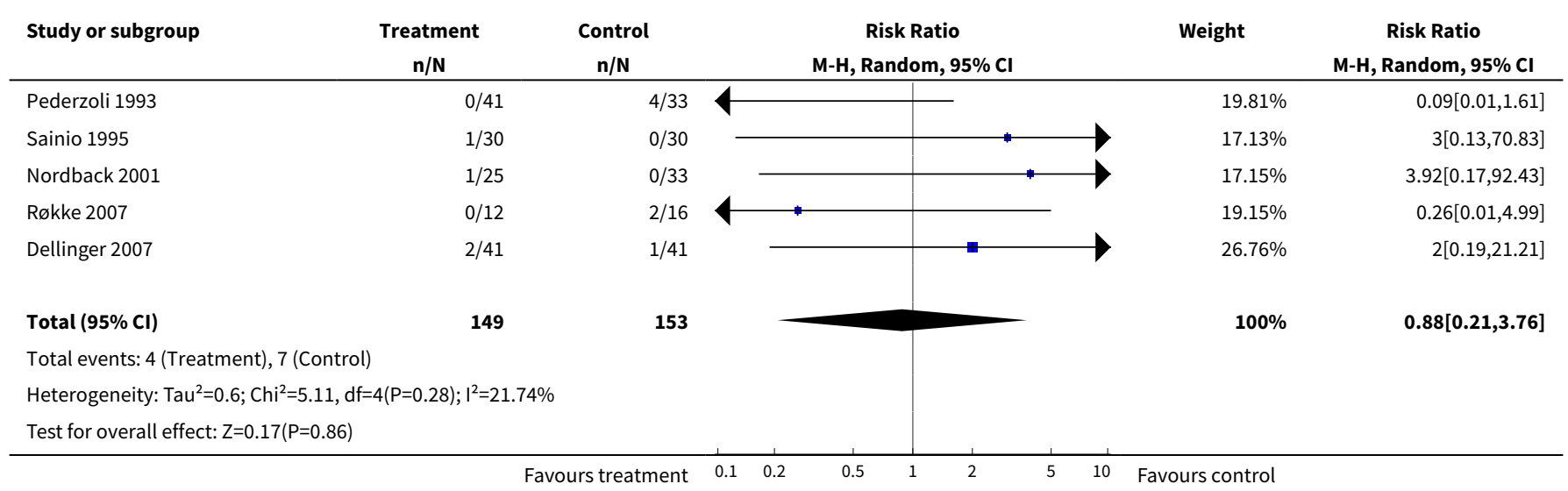


Analysis 2.6. Comparison 2 Beta-lactam versus control, Outcome 6 Operative Treatment (beta-lactam).

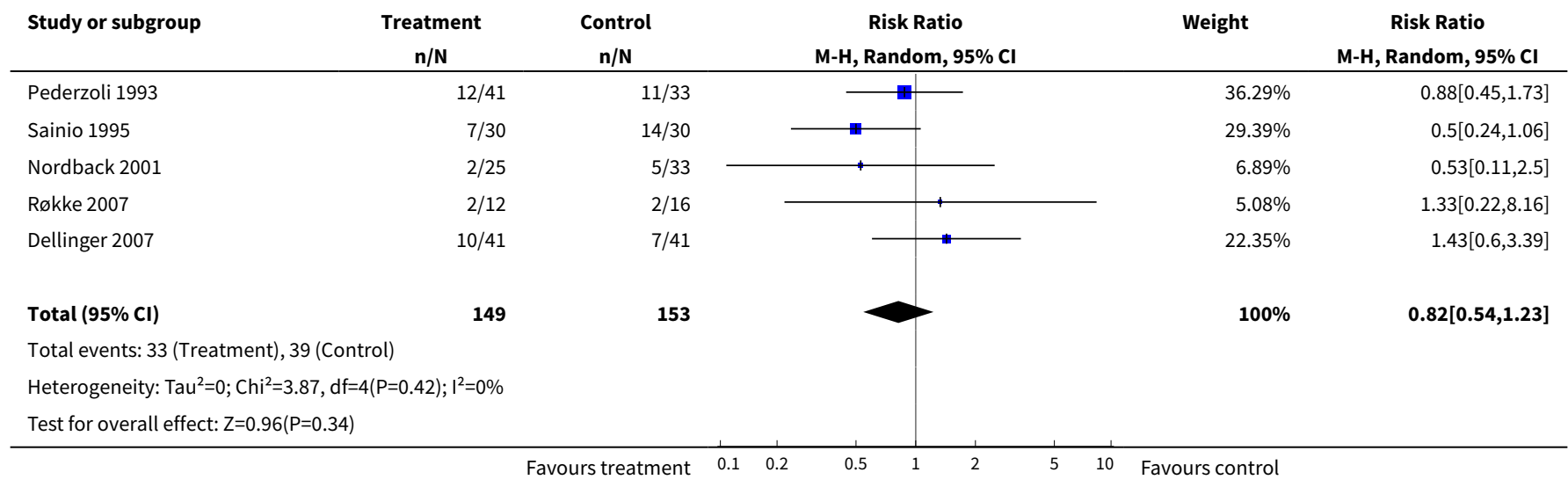

\section{Comparison 3. Quinolone versus control}

\begin{tabular}{llllll}
\hline Outcome or subgroup title & $\begin{array}{l}\text { No. of } \\
\text { studies }\end{array}$ & $\begin{array}{l}\text { No. of } \\
\text { partici- } \\
\text { pants }\end{array}$ & Statistical method & Effect size \\
\hline 1 Mortality (quinolones) & 2 & 102 & Risk Ratio (M-H, Random, 95\% Cl) & $0.51[0.14,1.85]$ \\
\hline $\begin{array}{l}2 \text { Infected Pancreatic Necrosis } \\
\text { (quinolones) }\end{array}$ & 2 & 102 & Risk Ratio (M-H, Random, 95\% Cl) & $1.16[0.66,2.03]$ \\
\hline 3 Fungal Infection (quinolones) & 2 & 102 & Risk Ratio (M-H, Random, 95\% Cl) & $1.30[0.32,5.21]$ \\
\hline
\end{tabular}

Analysis 3.1. Comparison 3 Quinolone versus control, Outcome 1 Mortality (quinolones).

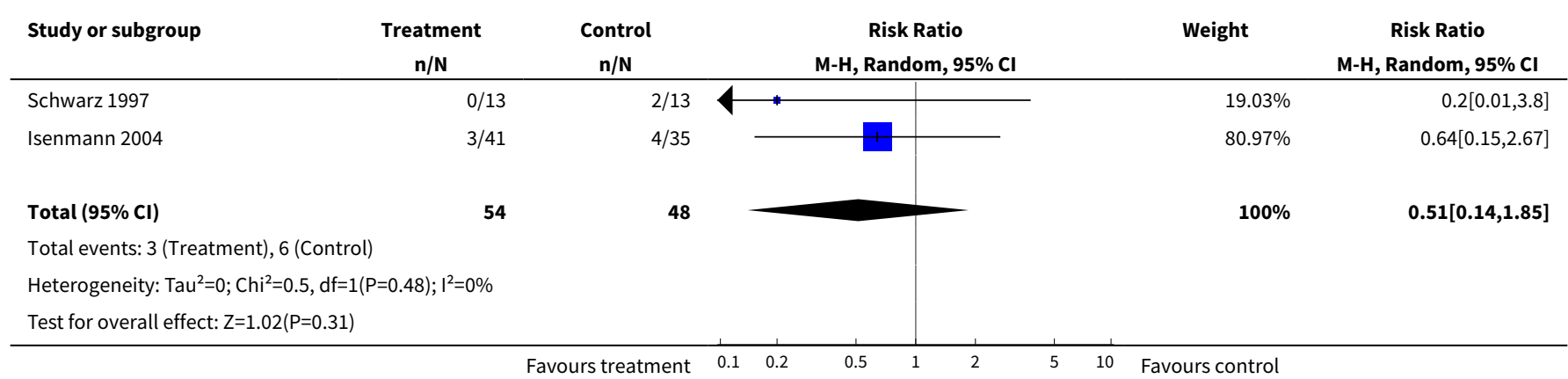

Analysis 3.2. Comparison 3 Quinolone versus control, Outcome 2 Infected Pancreatic Necrosis (quinolones).

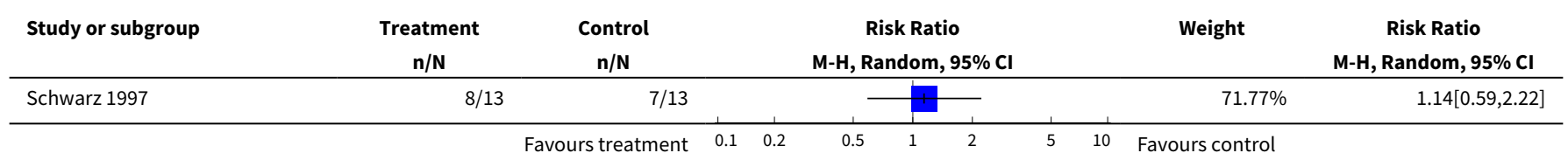




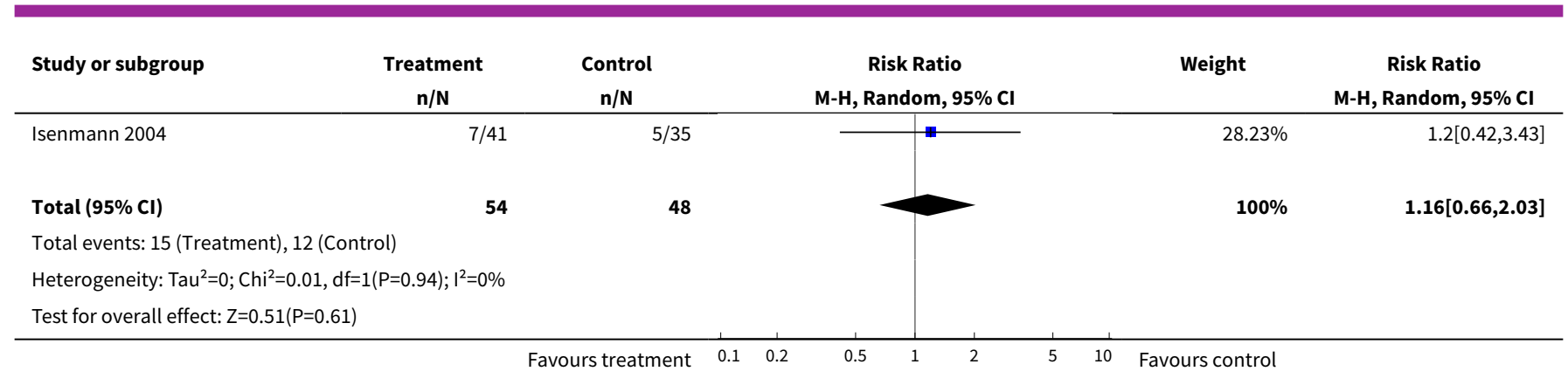

Analysis 3.3. Comparison 3 Quinolone versus control, Outcome 3 Fungal Infection (quinolones).

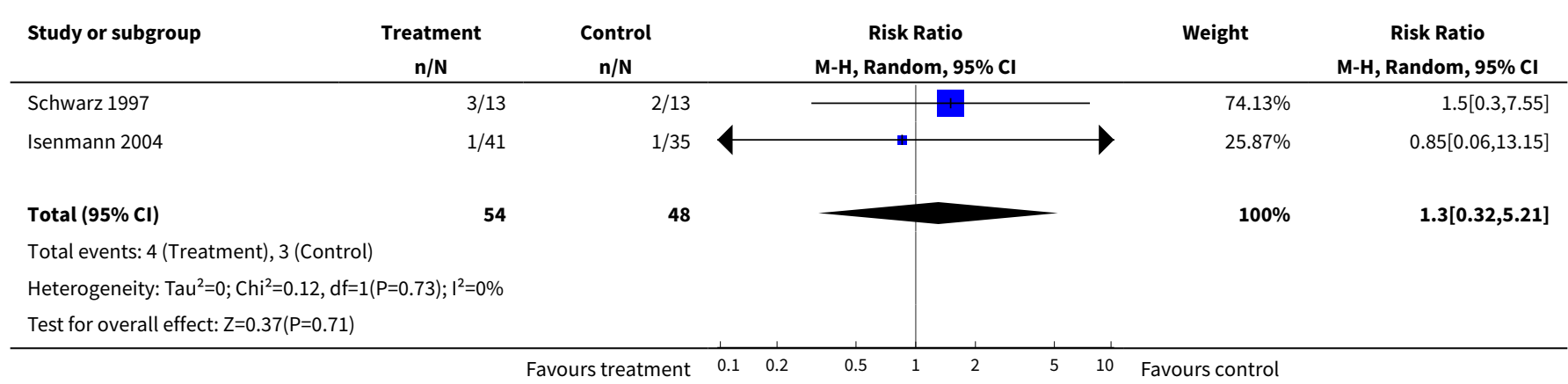

\section{Comparison 4. Imipenem versus control}

\begin{tabular}{lllll}
\hline Outcome or subgroup title & $\begin{array}{l}\text { No. of } \\
\text { studies }\end{array}$ & $\begin{array}{l}\text { No. of } \\
\text { partici- } \\
\text { pants }\end{array}$ & Statistical method & Effect size \\
\hline 1 Mortality (imipenem) & 3 & 160 & Risk Ratio (M-H, Random, 95\% Cl) & $0.70[0.28,1.75]$ \\
\hline $\begin{array}{l}2 \text { Infected Pancreatic Necrosis } \\
\text { (imipenem) }\end{array}$ & 3 & 160 & Odds Ratio (M-H, Random, 95\% Cl) & $0.34[0.13,0.84]$ \\
\hline $\begin{array}{l}3 \text { Non-pancreatic infections } \\
\text { (imipenem) }\end{array}$ & 3 & 160 & Risk Ratio (M-H, Random, 95\% Cl) & $0.67[0.16,2.77]$ \\
\hline \begin{tabular}{l}
4 All sites infections (imipenem) \\
\hline 5 Fungal Infection (imipenem)
\end{tabular} & 3 & 160 & Risk Ratio (M-H, Random, 95\% Cl) & $0.49[0.28,0.87]$ \\
\hline $\begin{array}{l}6 \text { Operative Treatment (imipen- } \\
\text { em) }\end{array}$ & 3 & 160 & Risk Ratio (M-H, Random, 95\% Cl) & $0.42[0.05,3.64]$ \\
\hline
\end{tabular}


Analysis 4.1. Comparison 4 Imipenem versus control, Outcome 1 Mortality (imipenem).

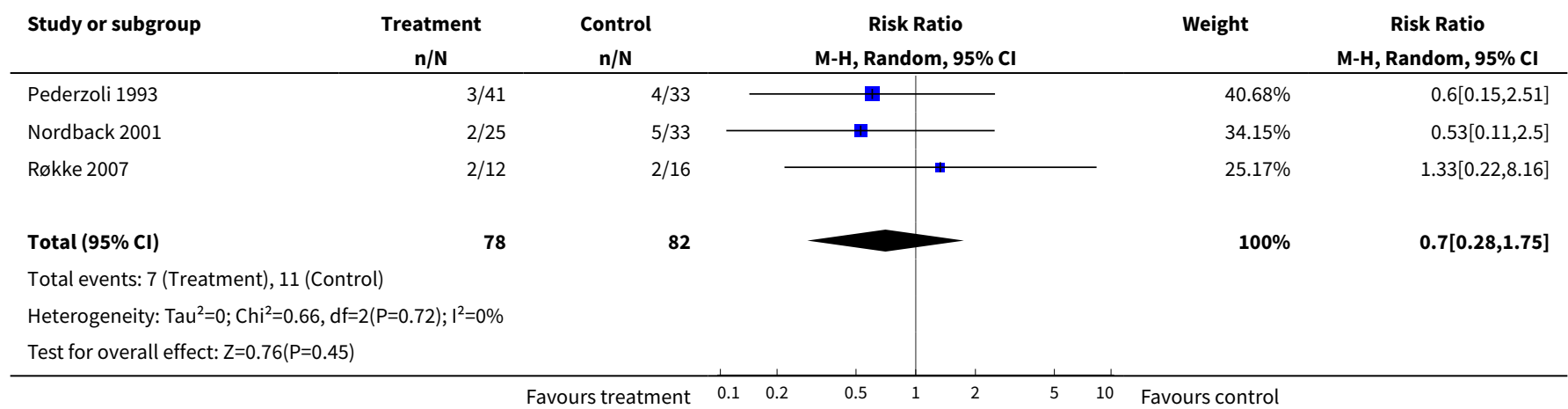

Analysis 4.2. Comparison 4 Imipenem versus control, Outcome 2 Infected Pancreatic Necrosis (imipenem).

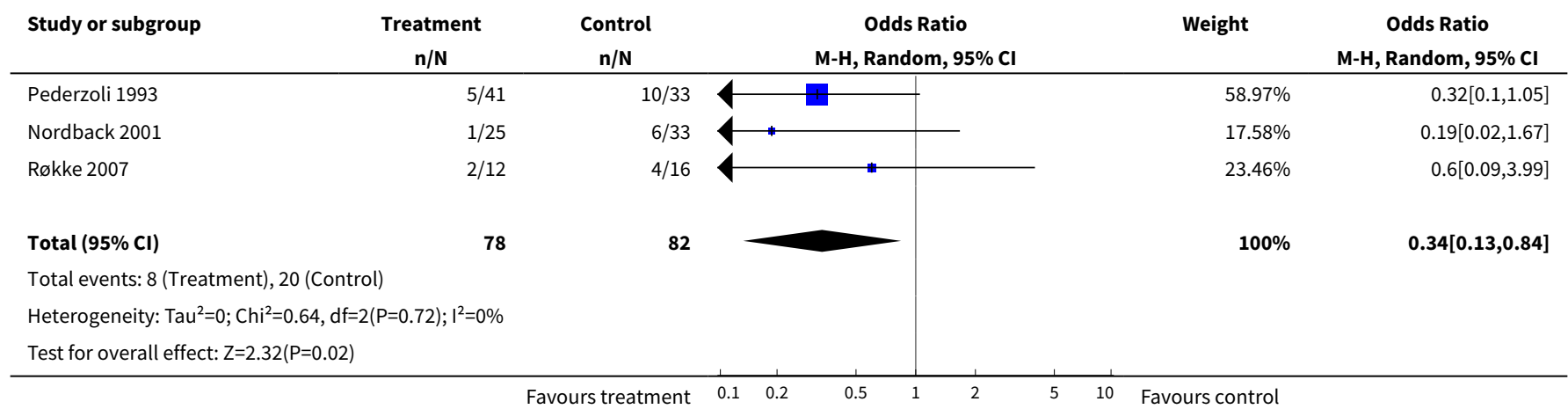

Analysis 4.3. Comparison 4 Imipenem versus control, Outcome 3 Non-pancreatic infections (imipenem).

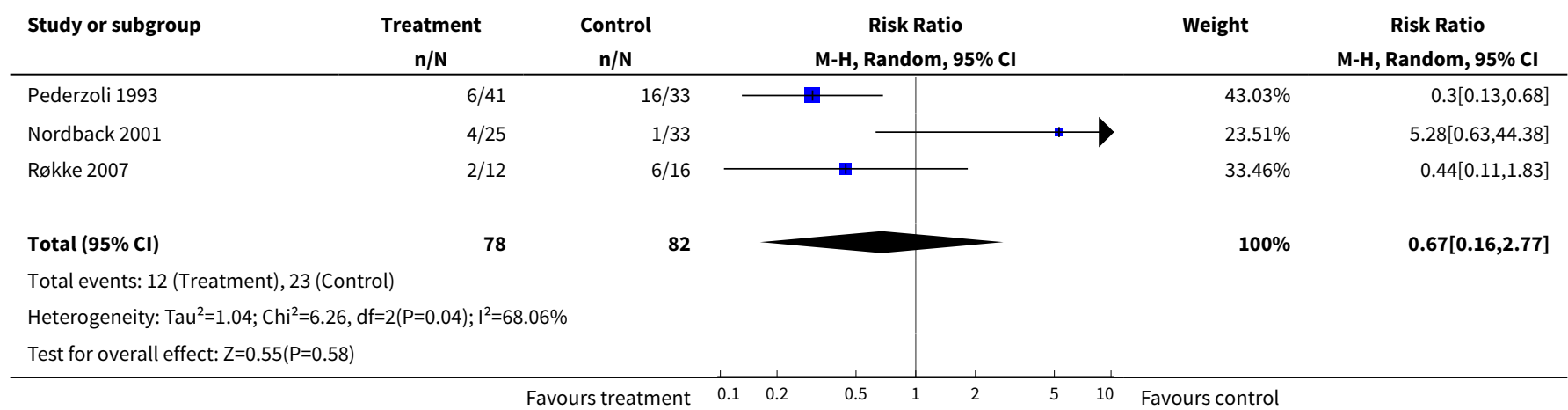

Analysis 4.4. Comparison 4 Imipenem versus control, Outcome 4 All sites infections (imipenem).

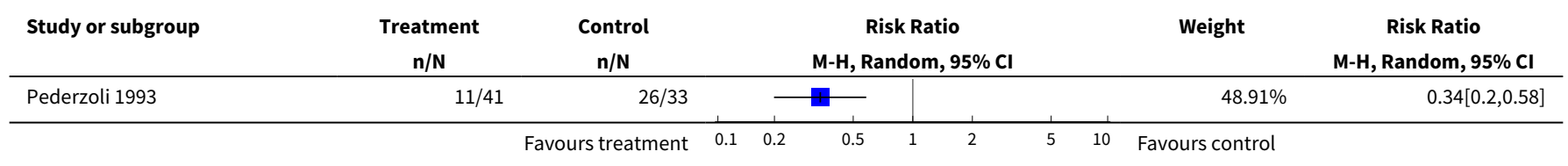




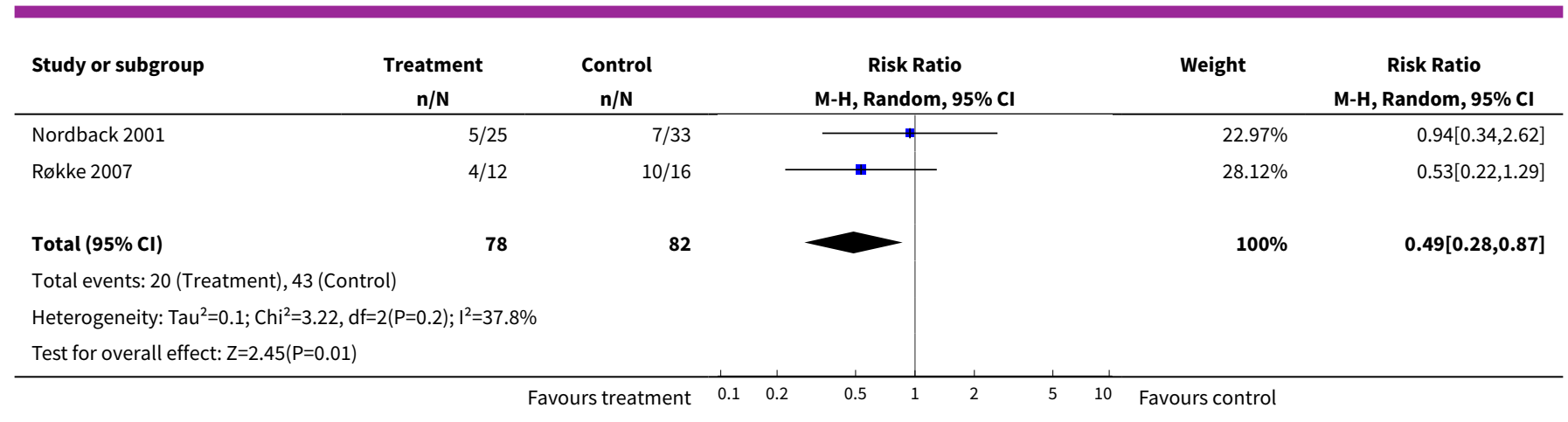

Analysis 4.5. Comparison 4 Imipenem versus control, Outcome 5 Fungal Infection (imipenem).

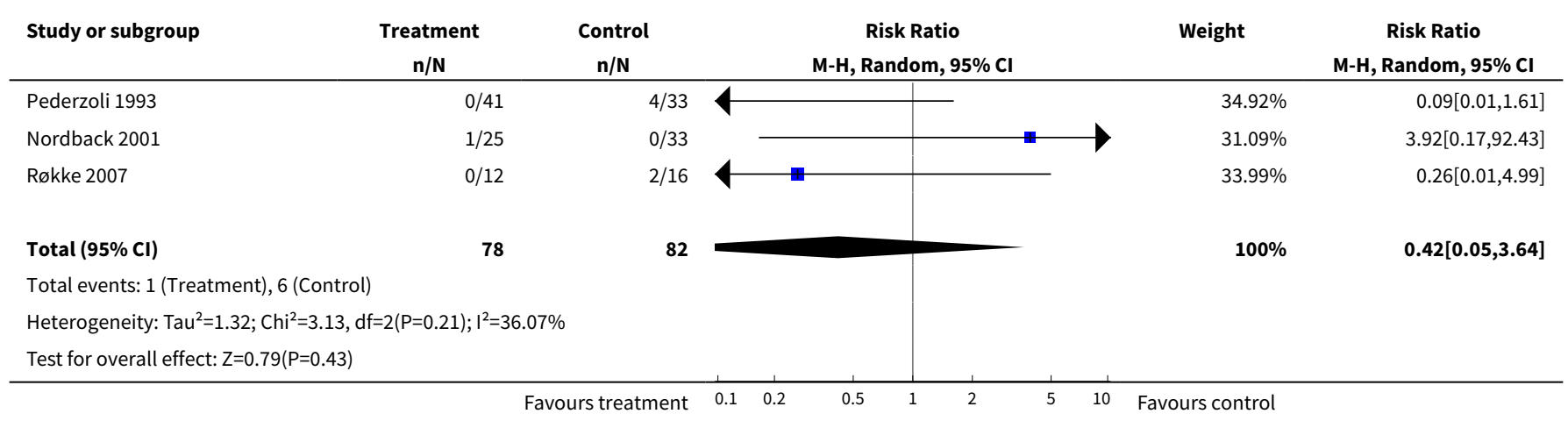

Analysis 4.6. Comparison 4 Imipenem versus control, Outcome 6 Operative Treatment (imipenem).

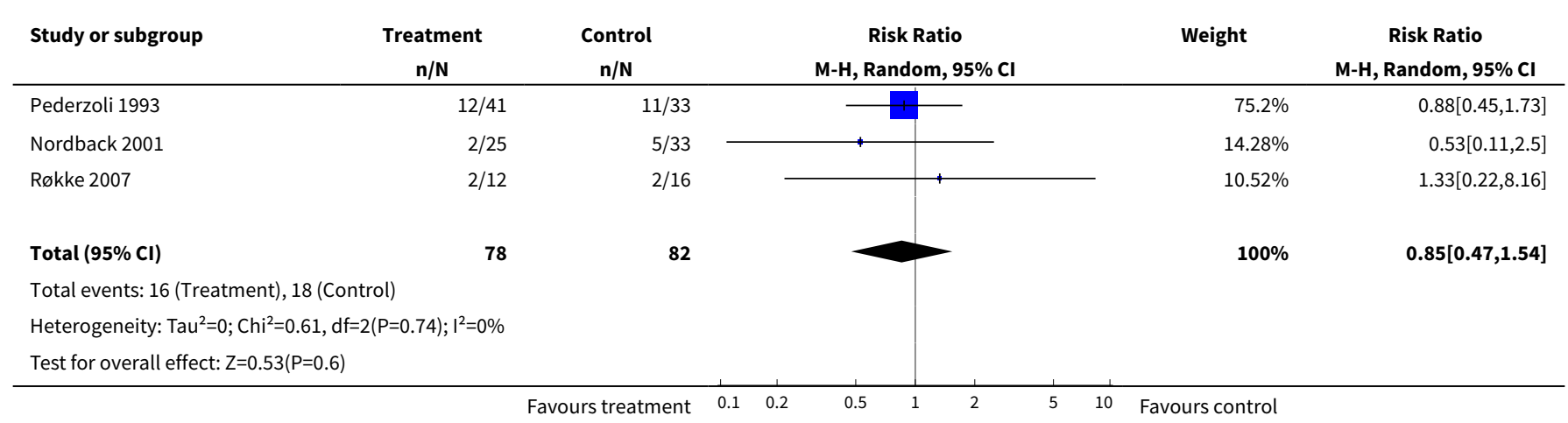

\section{APPENDICES}

\section{Appendix 1. MEDLINE search strategy}

1. exp pancreas/

2. exp pancreatitis/

3. pancreas.tw.

4. or/1-3

5. exp antibacterial agents/ 
6. antibacteria\$.tw.

7. exp antibiotic prophylaxis/

8. (antibiotic\$ or prophyla\$).tw.

9. cefotaxime.tw.

10. Aprotinin/

11. aprotinin\$.tw.

12. Gabexate/

13. gabexate mes?late.tw.

14. cefuroxime.tw.

15. imipenem.tw.

16. mezlocillin.tw.

17. gentam?cin\$.tw.

18. amikacin\$.tw.

19. pefloxacin\$.tw.

20. metronidazole.tw.

21. cephalosporin\$.tw.

22. or $/ 5-21$

23. 4 and 22

24. randomized controlled trial.pt.

25. controlled clinical trial.pt.

26. randomized.ab.

27. placebo.ab.

28. drug therapy.fs.

29. randomly.ab.

30. trial.ab.

31. groups.ab.

32. 24 or 25 or 26 or 27 or 28 or 29 or 30 or 31

33. humans.sh.

34.32 and 33

35.23 and 34 .

36. limit 35 to $y r=" 2006-2008 "$

37. from 36 keep 1-245

\section{Appendix 2. Embase search strategy}

1. exp pancreas/

2. exp pancreatitis/

3. pancrea\$.tw.

4. or/1-3

5. exp Antibiotic Agent/

6. $\exp$ Antibiotic prophylaxis/

7. (antibiotic\$ or prophyla\$).tw.

8. aprotinin\$.tw.

9. gabexate mes?late.tw.

10. cefuroxime.tw.

11. cefotaxime.tw.

12. imipenem.tw.

13. mezlocillin.tw.

14. gent?micin\$.tw.

15. amikacin\$.tw.

16. pefloxacin\$.tw.

17. metronidazole.tw.

18. cephalosporin\$.tw.

19. or $/ 5-18$

20.4 and 19

21. exp randomized controlled trial/

22. randomized controlled trial\$.tw.

23. exp randomisation/

24. exp single blind procedure/

25. exp double blind procedure/

26. or/21-25

27. animal.hw. 
28. human.hw.

29. 27 not (27 and 28)

30.26 not 29

31. exp clinical trial/

32. (clin\$ adj3 stud\$).ti,ab,tw.

33. (clin\$ adj3 trial\$).ti,ab,tw.

34. ((singl\$ or doubl\$ or treb\$ or tripl\$) adj3 (blind\$ or mask\$)).ti,ab,tw.

35. exp placebo/

36. placebo\$.ti,ab,tw.

37. random.ti,ab,tw.

38. (crossover\$ or cross-over\$).ti,ab,tw.

39. or $/ 31-38$

40.39 not 29

41.40 not 30

42. exp comparative study/

43. exp evaluation/

44. exp prospective study/

45. exp controlled study/

46. (control\$ or prospective $\$$ or volunteer $\$$ ).ti,ab,tw.

47. or/42-46

48.47 not 29

49.30 or 41 or 48

50.49 and 20

51. limit 50 to $y r=" 2006-2008 "$

52. limit 51 to (editorial or letter or note or proceeding or report or "review" or short survey)

53.51 not 52 .

54. from 53 keep 1-484

\section{Appendix 3. Cinahl search strategy}

1. exp pancreas/

2. exp pancreatitis/

3. pancrea\$.tw.

4. or/1-3

5. exp antibiotics/

6. (antibiotic\$ or prophyla\$).tw. [mp=title, subject heading word, abstract, instrumentation]

7. cefotaxime.tw.

8. cefuroxime.tw.

9. aprotinin\$.tw.

10. Aprotinin/

11. gabexate.tw.

12. imipenem.tw.

13. mezlocillin.tw.

14. gentam?cin\$.tw.

15. amikacin\$.tw.

16. pefloxacin\$.tw.

17. metronidazole.tw.

18. cephalosporin\$.tw.

19. or $/ 5-18$

20. 4 and 19

21. limit 20 to $y r=" 2006-2008 "$

22. limit 21 to "review"

23. 21 not 22

24. from 23 keep 1-53

\section{WHAT'S NEW}




\begin{tabular}{lll}
\hline Date & Event & Description \\
\hline 3 March 2010 & $\begin{array}{l}\text { New citation required and conclusions } \\
\text { have changed }\end{array}$ & Updated, new authors, new studies added, conclusions changed. \\
\hline 16 September 2009 & New search has been performed & Updated. \\
\hline
\end{tabular}

\section{HISTORY}

Protocol first published: Issue 1, 2001

Review first published: Issue 4, 2003

\begin{tabular}{lll}
\hline Date & Event & Description \\
\hline 15 August 2009 & $\begin{array}{l}\text { New citation required and conclusions } \\
\text { have changed }\end{array}$ & Substantive amendment \\
\hline 25 June 2009 & Amended & Converted to new review format. \\
\hline 11 June 2008 & New search has been performed & Conclusions changed, feedback added, minor update. \\
\hline 1 February 2008 & New search has been performed & New studies found and included or excluded. \\
\hline 1 October 2007 & New search has been performed & New studies found but not yet included or excluded. \\
\hline 24 January 2005 & Amended & Reformatted. \\
\hline
\end{tabular}

\section{CONTRIBUTIONS OF AUTHORS}

Claudio Bassi wrote a draft protocol for this study. Mike Larvin developed this for inclusion in the Cochrane Library. Eduardo Villatoro and Mike Larvin implemented the initial review (Villatoro 2003), and the 2006 revision (Villatoro 2006). Mubashir Mulla assisted Eduardo Villatoro and Mike Larvin with the present version of the review.

Study costs were met by the Academic Division of Surgery, School of Graduate Entry Medicine and Health, University of Nottingham, Derby (http://www.nottingham.ac.uk/mhs/gem), affiliated to the University's Wolfson Digestive Diseases Centre (http://www.nottingham.ac.uk/ wddc)

Fellowships for Eduardo Villatoro and Mubashir Mulla were funded by the Royal Derby Hospital NHS Foundation Trust. (http:// www.derbyhospitals.nhs.uk).

\section{DECLARATIONS OF INTEREST}

Professor Claudio Bassi was a co-author of one of the RCTs reviewed (Pederzoli 1993), but did not participate in the meta-analysis, discussion or conclusions. Professor Mike Larvin and Dr Eduardo Villatoro participated in the later stages of the international multi-centre study on the role of meropenem for prophylaxis against infection in pancreatic necrosis (Dellinger 2007). The study was sponsored by AstraZeneca who covered local administrative costs, and attendance for both at a mid-study conference during 2004. Neither investigator has received personal remuneration, nor were they involved as members of the study planning, analysis, or writing committees.

\section{SOURCES OF SUPPORT}

\section{Internal sources}

- Academic Division of Surgery, School of Graduate Entry Medicine and Health, University of Nottingham, Derby, UK.

- Royal Derby Hospital NHS Foundation Trust, Derby, UK.

- Wolfson Digestive Diseases Centre, University of Nottingham, UK. 


\section{External sources}

- No sources of support supplied

\section{DIFFERENCES BETWEEN PROTOCOLANDREVIEW}

We did not originally plan a formal sub-group analysis comparing imipenem plus cilastatin with control, but the availability of data published in new included studies led us to perform this additional sub-group analysis.

We elected to use risk ratios (RR) in this updated review and we employed a random effect meta-analysis model (instead of a fixed-effect one as in previous versions of this review) for all end-points where there was significant heterogeneity.

\section{NOT E S}

The review now includes the studies of Dellinger 2007 and Røkke 2007.

\section{N DEX TERMS}

\section{Medical Subject Headings (MeSH)}

*Antibiotic Prophylaxis; Acute Disease; Bacterial Infections [mortality] [ ${ }^{\star}$ prevention \& control]; Necrosis [complications]; Pancreas [* pathology]; Pancreatitis [ ${ }^{*}$ complications] [mortality]; Pancreatitis, Acute Necrotizing [complications]; Randomized Controlled Trials as Topic; Superinfection [ ${ }^{\star}$ prevention \& control]

\section{MeSH check words}

Humans 